University of Nebraska - Lincoln

DigitalCommons@University of Nebraska - Lincoln

\title{
Monoclonal Antibodies to Distinct Regions of Human Myelin Proteolipid Protein Simultaneously Recognize Central Nervous System Myelin and Neurons of Many Vertebrate Species
}

\author{
Edward A. Greenfield \\ Dana-Farber Cancer Institute \\ Jay Reddy \\ University of Nebraska - Lincoln, jayreddy@unl.edu \\ Andrew Lees \\ Biosynexus Inc. \\ Charissa A. Dyer \\ Children's Hospital Philadelphia \\ Omanand Koul \\ E.K. Shriver Center

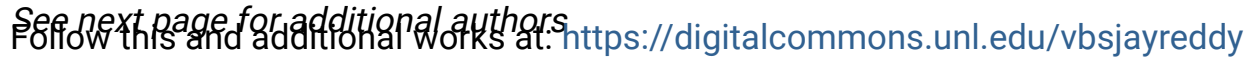 \\ Part of the Medical Immunology Commons, Medical Microbiology Commons, and the Medical \\ Molecular Biology Commons
}

Greenfield, Edward A.; Reddy, Jay; Lees, Andrew; Dyer, Charissa A.; Koul, Omanand; Nguyen, Khuong; Bell, Shannon; Kassam, Nasim; Hinojoza, Julian; Eaton, Mary Jane; Lees, Marjorie B.; Kuchroo, Vijay K.; and Sobel, Raymond A., "Monoclonal Antibodies to Distinct Regions of Human Myelin Proteolipid Protein Simultaneously Recognize Central Nervous System Myelin and Neurons of Many Vertebrate Species" (2006). Jay Reddy Publications. 4.

https://digitalcommons.unl.edu/vbsjayreddy/4

This Article is brought to you for free and open access by the Veterinary and Biomedical Sciences, Department of at DigitalCommons@University of Nebraska - Lincoln. It has been accepted for inclusion in Jay Reddy Publications by an authorized administrator of DigitalCommons@University of Nebraska - Lincoln. 


\section{Authors}

Edward A. Greenfield, Jay Reddy, Andrew Lees, Charissa A. Dyer, Omanand Koul, Khuong Nguyen, Shannon Bell, Nasim Kassam, Julian Hinojoza, Mary Jane Eaton, Marjorie B. Lees, Vijay K. Kuchroo, and Raymond A. Sobel 


\title{
Monoclonal Antibodies to Distinct Regions of Human Myelin Proteolipid Protein Simultaneously Recognize Central Nervous System Myelin and Neurons of Many Vertebrate Species
}

\author{
Edward A. Greenfield, ${ }^{1,2}$ Jayagopala Reddy, ${ }^{2}$ Andrew Lees, ${ }^{3}$ Charissa A. Dyer, ${ }^{4}$ \\ Omanand Koul, ${ }^{5}$ Khuong Nguyen, ${ }^{1}$ Shannon Bell, ${ }^{1}$ Nasim Kassam, ${ }^{2}$ \\ Julian Hinojoza, ${ }^{6,7}$ Mary Jane Eaton, ${ }^{6,7}$ Marjorie B. Lees, ${ }^{5}$ \\ Vijay K. Kuchroo, ${ }^{2}$ and Raymond A. Sobel ${ }^{6,7 \star}$ \\ ${ }^{1}$ Department of Adult Oncology, Dana-Farber Cancer Institute, Boston, Massachusetts \\ ${ }^{2}$ Center for Neurologic Diseases, Brigham and Women's Hospital, Boston, Massachusetts \\ ${ }^{3}$ Biosynexus Inc., Gaithersburg, Maryland \\ ${ }^{4}$ Department of Neurology, Abramson Research Center, Children's Hospital Philadelphia, \\ Philadelphia, Pennsylvania \\ ${ }^{5}$ Biomedical Sciences Division, E.K. Shriver Center, Waltham, Massachusetts \\ ${ }^{6}$ Laboratory Service, Veterans Affairs Health Care System, Palo Alto, California \\ ${ }^{7}$ Department of Pathology, Stanford University School of Medicine, Stanford, California
}

Myelin proteolipid protein (PLP), the major protein of mammalian CNS myelin, is a member of the proteolipid gene family (pgf). It is an evolutionarily conserved polytopic integral membrane protein and a potential autoantigen in multiple sclerosis (MS). To analyze antibody recognition of PLP epitopes in situ, monoclonal antibodies (mAbs) specific for different regions of human PLP (50-69, 100-123, 139-151, 178-191, 200-219, 264-276) were generated and used to immunostain CNS tissues of representative vertebrates. mAbs to each region recognized whole human PLP on Western blots; the anti-100-123 mAb did not recognize DM-20, the PLP isoform that lacks residues 116-150. All of the mAbs stained fixed, permeabilized oligodendrocytes and mammalian and avian CNS tissue myelin. Most of the mAbs also stained amphibian, teleost, and elasmobranch CNS myelin despite greater diversity of their pgf myelin protein sequences. Myelin staining was observed when there was at least $40 \%$ identity of the $\mathrm{mAb}$ epitope and known pgf myelin proteins of the same or related species. The pgf myelin proteins of teleosts and elasmobranchs lack 116-150; the anti-100-123 mAb did not stain their myelin. In addition to myelin, the anti-178$191 \mathrm{mAb}$ stained many neurons in all species; other mAbs stained distinct neuron subpopulations in different species. Neuronal staining was observed when there was at least approximately $30 \%$ identity of the PLP mAb epitope and known pgf neuronal proteins of the same or related species. Thus, anti-human PLP epitope mAbs simultaneously recognize CNS myelin and neurons even without extensive sequence identity. Widespread anti-PLP mAb recognition of neurons suggests a novel potential patho- physiologic mechanism in MS patients, i.e., that anti-PLP antibodies associated with demyelination might simultaneously recognize pgf epitopes in neurons, thereby affecting their functions. () 2006 Wiley-Liss, Inc.

Key words: demyelination; evolution; M6 proteins; multiple sclerosis; rhombex

Proteolipid protein (PLP), the major protein of mammalian CNS myelin, is an intrinsic membrane protein of oligodendrocytes with proposed roles in the formation and maintenance of myelin, intracellular transport, interactions with axons, and integrin signaling (Griffiths et al., 1998; Campagnoni and Skoff, 2001; Yool et al., 2001; Gudz et al., 2002). It is highly conserved among mammals; the sequences of murine and human PLP are identical. This conservation suggests that

Supplementary Material for this article is available online at http://www. interscience.wiley.com/jpages/0360-4012/suppmat/(www.interscience. wiley.com).

Edward A. Greenfield's current address is Millennium Pharmaceuticals, Inc., 75 Sidney Street, Cambridge, MA 02139.

^Correspondence to: Raymond A. Sobel, MD, Laboratory Service (113), Veterans Affairs Health Care System, 3801 Miranda Avenue, Palo Alto, CA 94304. E-mail: raysobel@stanford.edu

Received 27 July 2005; Revised 18 September 2005; Accepted 28 October 2005

Published online 13 January 2006 in Wiley InterScience (www. interscience.wiley.com). DOI: 10.1002/jnr.20748 
both the primary structure of PLP and its conformation in situ are critical for its functions. DM-20, the smaller isoform of PLP, is a minor component of mammalian CNS myelin. The DM protein members of the PLP/ DM-20 gene family (pgf; also referred to as "lipophilins"; Gow, 1997) are found in CNS myelin in bony fish and sharks, but they exhibit greater sequence diversity, suggesting their greater plasticity (Kitagawa et al., 1993; Geltner et al., 1998). Members of the pgf are also expressed in nonmyelinating cells, including neurons, in developing and mature vertebrate CNS tissues (Kitagawa et al., 1993; Yan et al., 1993, 1996; Roussel et al., 1998; Werner et al., 2001; Jacobs et al., 2003, 2004). To our knowledge, however, evolutionary conservation of pgf protein epitopes in situ has not been investigated.

PLP is a CNS autoantigen in demyelinating diseases (Greer et al., 1996a). We previously demonstrated that both naturally occurring and synthetic amino acid substitutions in PLP epitopes can dramatically alter Tcell responses and the induction of experimental autoimmune encephalomyelitis (Nicholson et al., 1995; Greer et al., 1997). Thus, small alterations of PLP epitopes can have profound effects on CNS autoimmunity. T-cell responses to PLP epitopes in patients with multiple sclerosis (MS) have been associated with clinical relapses (Pelfrey et al., 2000; Pender et al., 2000), and MS patients may have anti-PLP antibodies in their sera and cerebrospinal fluid (CSF). However, there currently is little information on anti-PLP antibody recognition of different PLP epitopes in CNS tissue or the potential pathophysiologic consequences of this recognition.

To understand PLP epitope binding, a panel of antibodies recognizing its distinct intra- and extracellular regions is needed (Greer and Lees, 2002). In the present study, PLP knockout $\left(\mathrm{PLP}^{-1-}\right)$ and wild-type mice were immunized with PLP and PLP peptides, and a large panel of monoclonal antibodies (mAbs) with reactivities to different PLP regions was generated. Selected mAbs were characterized for their reactivities to 1) whole PLP and PLP peptides by ELISA, 2) PLP and DM-20 on Western blots, and 3) live and fixed oligodendrocytes and normal human CNS tissue by immunohistochemistry. The results demonstrated the epitope specificity of the mAbs and their applicability to immunohistochemical studies of paraffin-embedded tissue samples.

To analyze $\mathrm{mAb}$ recognition of PLP epitopes in situ and assess their evolutionary conservation, archival CNS tissue samples from representative vertebrates were immunostained with the mAbs. In addition to staining CNS myelin, most of the mAbs also stained multiple neuron populations in each species. To understand the basis for this unexpected result, the occurrence of myelin and neuronal staining was then correlated with the degree of identity of the anti-PLP mAb epitope sequences and sequences of known major pgf myelin and neuronal proteins in the same or most closely related species. Myelin staining was frequently observed when there was as little as $40 \%$ sequence identity of the PLP mAb epitope and a known pgf myelin protein; neuronal staining was frequently observed when there was as little as 30\% sequence identity with a known pgf neuronal protein. These results suggest that anti-PLP mAbs may recognize evolutionarily conserved epitopes present not only in CNS myelin but also in mature neurons. Insofar as an $\mathrm{mAb}$ to pgf M6 neuronal proteins inhibits neuronal development and function in vitro, the results raise the possibility that, in MS patients with anti-PLP antibodies associated with demyelination, similar recognition of neuronal pgf protein epitopes might contribute to dysfunction, degeneration, or impaired regeneration of neurons in vivo. Thus, the cross-reactivity of PLP mAbs suggests a new potential pathogenetic mechanism in MS.

\section{MATERIALS AND METHODS}

\section{Mice}

Female BALB/c mice, 4-8 weeks old, were purchased from Harlan Sprague Dawley, Inc. (Indianapolis, IN). PLP ${ }^{-1-}$ mice were obtained from Klaus-Armin Nave (Max-Planck Institute of Experimental Medicine, Göttingen, Germany) (Klugmann et al., 1997) and were bred onto the SJL background. (SJL $\times$ B10.BR) $F_{1}$ mice were bred at The Children's Hospital of Philadelphia Laboratory Animal Facility. All animals were acquired and maintained in accordance with the guidelines of the Institutional Animal Care and Use Committees of Harvard Medical School, E.K. Shriver Center, and The Children's Hospital of Philadelphia.

\section{PLP and PLP Peptides}

PLP was isolated from frozen samples of human post-mortem brain tissue and bovine brain, as previously described (Greer et al., 1996a, 1997). All PLP preparations contain both PLP and DM-20. All peptides were synthesized by using F-moc chemistry and were greater than $90 \%$ pure by HPLC analysis. Peptides either were synthesized in the laboratory of Dr. Richard Laursen, Department of Chemistry, Boston University, or were a generous gift of Dr. David Hafler, Department of Neurology, Harvard Medical School (Marcovic-Plese et al., 1995).

\section{Generation of PLP Antibodies}

One hundred micrograms of human PLP were suspended in Dulbecco's phosphate-buffered saline (PBS; Gibco, Grand Island, NY) and emulsified with an equal volume of complete Freund's adjuvant (Sigma Chemical Co., St. Louis, MO). Mice were immunized by injection of the emulsion at three subcutaneous sites. Fourteen days after the initial immunization, the mice were given a booster immunization i.p. with $100 \mu \mathrm{g}$ human PLP suspended in PBS and emulsified with an equal volume of incomplete Freund's adjuvant. A second booster was given after another 14 days. Ten days later, a small amount of blood was collected by retroorbital bleeding, and the serum activity against PLP was titered by ELISA. Mice were selected for cell fusion when the titer exceeded 1:24,300. Rat anti-PLP $264-276 \mathrm{mAb}$ AA3 $\left(\mathrm{IgG}_{2 \mathrm{~b}}\right)$ or AB3 $\left(\mathrm{IgG}_{2 \mathrm{a}}\right.$; Yamamura et al., 1991) were used as positive controls.

The selected mice were rested for 4 weeks after the last immunization and then boosted by intravenous injection with 
either $50 \mu \mathrm{g}$ PLP or synthetic PLP peptide in PBS. Four days later, the mice were sacrificed, and spleen cell suspensions were prepared and washed with PBS. Spleen cells were counted and mixed with SP 2/0 myeloma cells (ATCC No. CRL8-006, Rockville, MD) that are incapable of secreting either heavy or light immunoglobulin chains (Kearney et al., 1979) at a spleen:myeloma cell ratio of 2:1. Cells were fused with polyethylene glycol 1450 (ATCC) in 12 96-well tissue culture plates in HAT selection medium according to standard procedures (Kohler and Milstein, 1975).

\section{Screening and Expansion of Hybridomas}

Between 10 and 21 days after fusion, hybridoma colonies became visible, and culture supernatants were harvested and screened by ELISA. High-protein-binding 96-well EIA plates (Costar, Cambridge, MA) were coated with $50 \mu \mathrm{l} /$ well of a $5 \mu \mathrm{g} / \mathrm{ml}$ solution $(0.1 \mu \mathrm{g} /$ well $)$ of PLP or synthetic PLP peptides and incubated overnight at $4^{\circ} \mathrm{C}$. The excess solution was aspirated, and the plates were washed with PBS (three times) and blocked with $1 \%$ bovine serum albumin (BSA) solution for $1 \mathrm{hr}$ at room temperature (RT) to inhibit nonspecific binding. The BSA solution was removed, and $50 \mu \mathrm{l} /$ well of hybridoma supernatant from each fusion plate were added. The plates were then incubated for $45 \mathrm{~min}$ at $37^{\circ} \mathrm{C}$ and washed three times with PBS. Horseradish peroxidase (HRP)conjugated goat anti-mouse Ig (Zymed, South San Francisco, CA) diluted 1:4,000 in 1\% BSA/PBS was added to each well, and the plates were incubated for $45 \mathrm{~min}$ at $37^{\circ} \mathrm{C}$. After washing, $50 \mu \mathrm{l} /$ well of ABTS (Zymed) were added. The intensity of the green color of positive wells at $405 \mathrm{~nm}$ was assessed on a Vmax microtiter plate reader (Molecular Devices Corp., Sunnyvale, CA). All hybridoma wells that gave a positive response were then expanded to 24-well cultures, subcloned by limiting dilution, and analyzed by ELISA. The three best producing subclones were expanded further. Supernatants were isotyped with an Isostrip kit (Boehringer Mannheim Corp., Indianapolis, IN).

\section{Antibody Purification}

The antibodies were purified using Millipore Prosep Protein A resin. They were diafiltered into PBS and concentrated with an Amicon Ultra 4 (30-kDa cutoff) device according to the manufacturer's protocol.

\section{Epitope Identification by ELISA}

The antibodies selected from the fusions were screened by ELISA to determine the epitope or region of PLP that they recognized. Each antibody supernatant was screened against a panel of overlapping PLP peptides (1-19, 10-29, 2039 , 30-49, 50-69, 60-79, 80-99, 100-119, 110-123, 110129, 120-139, 130-149, 139-151, 140-159, 150-169, 170189, 178-191, 180-199, 190-209, 200-219, 215-232, 220239, 240-259, 250-269, 260-276, and 269-276), human and bovine PLP, and bovine MBP. The peptides were dissolved in $0.1 \mathrm{M}$ bicarbonate buffer, $\mathrm{pH} 9.0$, and bound overnight to EIA plates with $50 \mu \mathrm{l} /$ well of a $5 \mu \mathrm{g} / \mathrm{ml}$ solution $(0.25 \mu \mathrm{g} /$ well) and then processed as described above.

\section{Immunoblots}

Fifty micrograms of human PLP were mixed with sample buffer containing $0.7 \%$ dithiothreitol, $1 \mathrm{mM}$ EDTA, $10 \mathrm{mM}$ Tris- $\mathrm{HCl}, 5 \%$ sodium dodecyl sulfate (SDS), 13\% glycerol, and $0.007 \%$ bromophenol blue and electrophoresed on a $12 \%$ SDS-PAGE under reducing conditions. The proteins were transferred onto nitrocellulose membranes (BioRad, Hercules, CA) and treated with blocking buffer $(50 \mathrm{mM}$ Tris, $150 \mathrm{mM} \mathrm{NaCl}, 0.05 \%$ Tween, 5\% dry milk solids) for $1 \mathrm{hr}$ at RT. The membranes were probed overnight with the purified PLP-specific Ab at a concentration of $200 \mathrm{ng} / \mathrm{ml}$ in buffer containing 5\% BSA and 0.025\% sodium azide. After washing, the membranes were incubated with HRP-labeled goat anti-mouse $\mathrm{Ab}(0.4 \mathrm{mg} / \mathrm{ml}$; Jackson Immunoresearch, West Grove, PA) in the above-mentioned buffer for $1 \mathrm{hr}$. The membranes were then washed and autoradiographed by using an ECL Western blotting detection kit (Amersham Biosciences, Piscataway, NJ) according to the manufacturer's recommendations.

\section{Immunofluorescent Staining of Mouse Oligodendrocytes}

Oligodendrocyte-enriched shake-off cultures were prepared from 2-day-old $(\mathrm{SJL} \times \mathrm{B} 10) \mathrm{F}_{1}$ newborn mice by using a modified version of the method of McCarthy and de Vellis (1980) as described by Dyer et al. (1995). Live cultures were treated with undiluted hybridoma supernatant, followed by addition of appropriate fluorescein isothiocyanate (FITC; Boehringer Mannheim Corp.) or TRITC (Jackson Immunoresearch) goat anti-mouse $\operatorname{IgG}$ or $\operatorname{IgM}$ secondary antibody diluted 1:40. Each step was carried out for $15 \mathrm{~min}$ at $37^{\circ} \mathrm{C}$ in $5 \% \mathrm{CO}_{2}$. To detect internal epitopes, the cells were fixed in $4 \%$ paraformaldehyde for $5 \mathrm{~min}$ and permeabilized with $0.05 \%$ saponin for 15 min prior to staining with the supernatant or primary $\mathrm{mAb}$. The $\mathrm{O} 4$ hybridoma was grown and purified as described elsewhere (Dyer et al., 1995). SMI-99 mouse $\mathrm{mAb}$ reactive with myelin basic protein $(\mathrm{MBP})$ was purchased from Sternberger Monoclonals (Baltimore, MD). Images were captured with a 35-mm camera system on a Leitz DMR fluorescent microscope with Tmax ASA 400 film.

\section{Tissue Samples}

Archival samples of routinely fixed, paraffin-embedded CNS tissue from our previous studies and additional samples of vertebrate CNS tissues were obtained from other investigators. Six-micrometer-thick serial sections from each paraffin block were stained with Luxol fast blue-H\&E stain and with the mAbs by immunohistochemistry. A human CNS tissue block contained at least three levels of normal spinal cord from an autopsy of a 24-year-old male. The nonhuman samples consisted of a cow brainstem ( $\mathrm{N}=3$ blocks), two rabbit brains ( $\mathrm{N}=2$ blocks), three Lewis rat brains ( $\mathrm{N}=3$ blocks), the brains and spinal cords of SJL/J and C57/B16 mice $(\mathrm{N}=$ 2 blocks each), the brains and spinal cords of three Rana pipiens ( $\mathrm{N}=3$ blocks), two Xenopus brains ( $\mathrm{N}=2$ blocks), and one block each from the brains of a barn owl, a Malawi cichlid, and a leopard shark. All vertebrate species had Luxol fast blue-positive myelin. 
TABLE I. pgf Proteins

\begin{tabular}{|c|c|c|c|c|c|c|}
\hline $\begin{array}{l}\text { Vertebrate } \\
\text { group }\end{array}$ & $\begin{array}{l}\text { Myelin pgf } \\
\text { proteins }\end{array}$ & $\begin{array}{c}\text { Accession } \\
\text { number }\end{array}$ & Abbreviation $^{\mathrm{a}}$ & $\begin{array}{l}\text { Neuronal } \\
\text { pgf proteins }\end{array}$ & $\begin{array}{l}\text { Accession } \\
\text { number }\end{array}$ & Abbreviation $^{a}$ \\
\hline \multirow[t]{5}{*}{ Mammals } & Bovine PLP & P04116 & bPLP & Human M6a & P51674 & hM6a \\
\hline & Rat PLP & P60203 & rtPLP & Rat M6a & Q812E9 & rtM6a \\
\hline & Mouse PLP & P60202 & mPLP & Rhombex-29 & Q9JJK1 & Rh-29 \\
\hline & & & & Mouse M6a & P35802 & mM6a \\
\hline & & & & Mouse M6b & P35803 & $\mathrm{mM} 6 \mathrm{~b}$ \\
\hline \multirow[t]{4}{*}{ Amphibians } & Xenopus PLP1 & P35801 & Xe PLP1 & Xenopus DM $\beta$ & Q98ST4 & $\mathrm{Xe} D M \beta$ \\
\hline & Xenopus PLP2 & P23290 & Xe PLP2 & & & \\
\hline & Xenopus DM 11 & Q98ST3 & $\mathrm{Xe} \mathrm{DM} \gamma 1$ & & & \\
\hline & Xenopus DM 2 /GPM6b & Q98ST2 & $\mathrm{Xe} D M \gamma 2 / \mathrm{M} 6 \mathrm{~b}^{\mathrm{c}}$ & & & \\
\hline \multirow[t]{3}{*}{ Teleosts } & Rainbow trout DM20 & P79826 & RTr DM20 & Zebrafish M6a & Q8UUT4 & Zfsh M6a \\
\hline & Zebrafish DM $\alpha 1$ & Q8UUT6 & Zfsh DM $\alpha 1$ & Zebrafish Gpm6ab & Q6D117 & Zfsh M6b \\
\hline & Zebrafish DM ${ }^{2} 2$ & Q8UUS8 & Zfsh DM 22 & & & \\
\hline \multirow[t]{3}{*}{ Elasmobranchs } & Squalus $D M \alpha^{\mathrm{c}}$ & P36963 & $\mathrm{Sq} \mathrm{DM} \alpha$ & & & \\
\hline & Squalus $D M \beta^{c}$ & P36964 & Sq DM $\beta$ & & & \\
\hline & Squalus $D M \gamma^{c}$ & P36965 & Sq DM $\gamma$ & & & \\
\hline
\end{tabular}

${ }^{a}$ The sequences of the pgf proteins listed were compared to with the human PLP sequences. The abbreviations are used in Supplemental Tables A-C.

${ }^{\mathrm{b}}$ UniProtKB/Swiss-prot or/TrEMBL entry.

${ }^{c}$ The Xenopus DMr2/GPM6b protein sequence and the squalus DM protein sequences were used for analyses of both myelin and neuronal staining.

\section{Tissue Immunohistochemistry}

Six anti-PLP mAbs generated in the present study (two to 50-69 and one each to 100-123, 178-191, 200-219, and 264-276) were used for the immunohistochemical analyses. This panel was supplemented with the previously described mouse $\mathrm{mAbs}$ to $139-151$ (1D5 and $1 \mathrm{C} 5$, both $\mathrm{IgG}_{1}$; Greer et al., 1996b) and a rat mAb to 264-276 (AA3, IgG 2 ; Yamamura et al., 1991). Reactivities of the nine purified $\mathrm{mAb}$ supernatants in the tissue sections were titered for optimal staining using immunoperoxidase staining as described elsewhere (Sobel, 2005). Controls included substitution of $\mathrm{mAb}$ supernatants with PBS.

\section{Sequence Comparisons}

Percentages of sequence identities to the human PLP $\mathrm{mAb}$ epitopes were determined from BLAST searches (http:// au.expasy.org/tools/blast/) and estimated by aligning sequences of the pgf myelin or neuronal proteins in the same or most closely related species for which the sequences are known (Table I). The pgf proteins listed are at least 30\% identical to one or more of the PLP mAb epitopes.

\section{RESULTS}

\section{Selection of Antibodies}

Approximately 8,000 hybridomas were generated from fusions of spleens from six $\mathrm{PLP}^{-/-}$mice and one $\mathrm{BALB} / \mathrm{c}$ mouse that had been immunized with human PLP and boosted with synthetic PLP peptides. After ini- tial screening against human PLP, 25 reactive hybridomas were identified, subcloned, and isotyped. In additional testing, two of these showed consistent reactivity to the region encompassing PLP 50-69, one to PLP 100-123, two to PLP 178-191, five to PLP 200-219, and one to PLP 264-276. Eleven hybridomas initially showed reactivity to PLP 139-151, but this reactivity was not consistent through subcloning; all but one of those hybridomas were determined to be of the IgM subclass. Three hybridomas showed reactivity to whole PLP but did not show consistent reactivity to any of the peptides tested. Thus, their epitope specificities could not be determined.

\section{Epitope Assignments}

Table II shows the reactivities to PLP and representative PLP peptides of selected hybridomas. All of these mouse hybridomas recognize human and bovine PLP and not MBP. Each hybridoma shown specifically recognizes a different region of human PLP. Based on these and additional ELISA screening using overlapping peptides, assignments for reactivity of the mAbs used for further studies were made as follows: F4.4C2 and F3.9E9 (PLP 50-69), F4.2D2 (PLP 100-123), P7.6A5 (PLP178-191), F4.8A5 (PLP 200-219), and P5.12A8 (PLP 264-276). Hybridoma P5.12A8 is an IgM; F3.9E9 is an $\mathrm{IgG}_{2 \mathrm{a \kappa}}$; all of the other hybridomas are $\mathrm{IgG}_{1 \kappa}$. All but one of these selected hybridomas were from PLP $^{-1-}$ mice; the anti-PLP 178-191 hybridoma was from the 
TABLE II. Epitope Mapping of Representative PLP Antibodies by ELISA

\begin{tabular}{|c|c|c|c|c|c|c|c|c|c|c|}
\hline \multirow[b]{3}{*}{ Hybridoma } & \multirow{3}{*}{$\begin{array}{c}\text { Epitope } \\
\text { assignment }\end{array}$} & \multicolumn{9}{|c|}{ Absorbance $(\mathrm{OD} / 405 \mathrm{~nm})^{\mathrm{a}}$} \\
\hline & & \multirow[b]{2}{*}{ MBP } & \multirow{2}{*}{$\begin{array}{l}\text { Human } \\
\text { PLP }\end{array}$} & \multirow{2}{*}{$\begin{array}{l}\text { Bovine } \\
\text { PLP }\end{array}$} & \multicolumn{6}{|c|}{ PLP peptide tested } \\
\hline & & & & & $50-69$ & $120-139$ & $139-151$ & $178-191$ & $200-219$ & $260-276$ \\
\hline $\mathrm{F} 4.4 \mathrm{C} 2$ & $50-69$ & 0.078 & 0.699 & 1.070 & 0.433 & 0.057 & 0.059 & 0.107 & 0.071 & 0.074 \\
\hline $\mathrm{F} 4.2 \mathrm{D} 2$ & $100-123^{\mathrm{b}}$ & 0.060 & 0.584 & 1.149 & 0.047 & 0.409 & 0.043 & 0.050 & 0.048 & 0.058 \\
\hline P7.6A5 & $178-191$ & 0.052 & 0.487 & n.d. ${ }^{\mathrm{c}}$ & 0.094 & 0.075 & 0.076 & 0.656 & 0.089 & 0.076 \\
\hline F4.8A5 & $200-219$ & 0.056 & 0.379 & 0.921 & 0.045 & 0.043 & 0.046 & 0.047 & 0.653 & 0.053 \\
\hline
\end{tabular}

${ }^{\mathrm{a}}$ Italicized values indicate positive results.

${ }^{\mathrm{b}}$ Assignment based on reactivity with PLP 100-119, 110-123, 110-129, and 120-139 but not with peptide 130-149 or 139-151.

${ }^{c}$ n.d., Not done.

$\mathrm{BALB} / \mathrm{c}$ mouse. In additional testing by ELISA of one of the previously reported anti-139-151 mAbs (1C5), the specific reactivity of this $\mathrm{mAb}$ to a synthetic peptide encompassing the 139-151 region and lack of reactivity to a peptide encompassing the 100-123 region confirmed its specificity.

\section{Western Blots}

A representative Western blot demonstrates that all five of the hybridomas tested recognize a band corresponding to PLP (Fig. 1). All but one $\mathrm{mAb}$ also recognize a slightly lower band corresponding to DM-20. Because this $\mathrm{mAb}$ recognizes PLP 100-123, it does not recognize DM-20, and there is a single band on the blot. None of the mAbs recognized MBP (not shown).

\section{Immunofluorescent Staining of Cultured Oligodendrocytes}

Only the one anti-50-69 mAb (F4.4C2) of the five mAbs tested detected a PLP epitope on the surface of cultured oligodendrocytes. A prominent membrane staining pattern is evident in Figure 2A,B. Figure 2C shows the same cells shown as in Figure $2 \mathrm{~B}$ stained with the oligodendrocyte marker antibody O4, confirming that the cells are oligodendrocytes. However, the distributions of PLP and antibody O4 are distinct: O4 is uniformly distributed, whereas PLP occurs in a punctate pattern throughout the sheet and is also concentrated along the edges (compare areas indicated by arrows in Fig. 2B,C).

The mAbs recognizing PLP peptides 100-123, 178-191, 200-219, and 264-276 did not stain the surface of live oligodendrocytes. Representative results for the $\mathrm{mAb}$ to PLP 264-276 are shown in Figure 2D. However, each of the $\mathrm{mAbs}$ to these regions stained fixed and permeabilized oligodendrocytes. Figure 2E shows a representative fixed oligodendrocyte stained for PLP 264-276 with this mAb. PLP 264-276 has been shown to be on the cytoplasmic portion of the membrane (Konola et al., 1992), and staining for this epitope shows a distribution in the cell body, along cytoskeletal veins, and in the membrane sheet (highlighted by arrows). Figure $2 \mathrm{~F}$ shows the same cell stained for MBP.

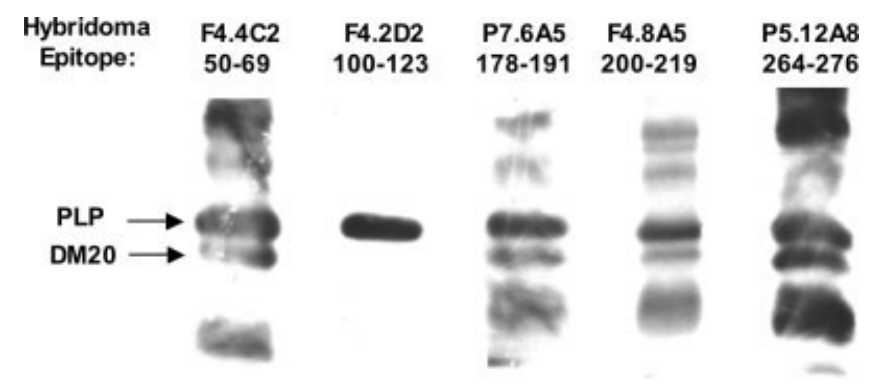

Fig. 1. Representative immunoblot of whole human PLP with selected mAbs. With one exception, i.e., the mAb to 100-123, all of the $\mathrm{mAbs}$ tested recognize two bands corresponding to PLP and DM-20. The 100-123 epitope is part of the region absent in DM-20 (residues 116-150). Therefore, the $\mathrm{mAb}$ to this region stains only PLP and not DM-20. The higher molecular weight bands represent aggregates of multimeric complexes and the lower bands are presumed degradation products. All but the mAb to 200-219 were run in the same gel. The data are representative of six gels performed for different human PLP samples.

The staining pattern for MBP differs from that of PLP 264-276 in that it appears more diffuse (compare areas indicated by arrows in Fig. 2E,F). In summary, only an anti-50-69 mAb immunostained live oligodendrocytes, confirming that this region is on the extracellular face of the membrane, whereas all of the other mAbs tested stained fixed, permeabilized oligodendrocytes.

\section{Immunostaining of Archival Paraffin Sections}

For each of the purified mAbs, optimal staining was observed at dilutions of 1:100-1:500; diffuse and nonspecific patterns were observed when they were more concentrated. The three pairs of $m A b s$ to the same regions (50-69, 139-151, and 264-276) gave essentially identical staining results. Staining controls were negative.

\section{Mammalian and Avian CNS Myelin}

In the normal human spinal cord, all anti-PLP mAbs specifically stained CNS myelin, but not PNS myelin or axons in adjacent spinal nerve roots (Fig. 3AF). In gray matter areas, e.g., the posterior horns, they stained individual myelinated fibers but not the back- 

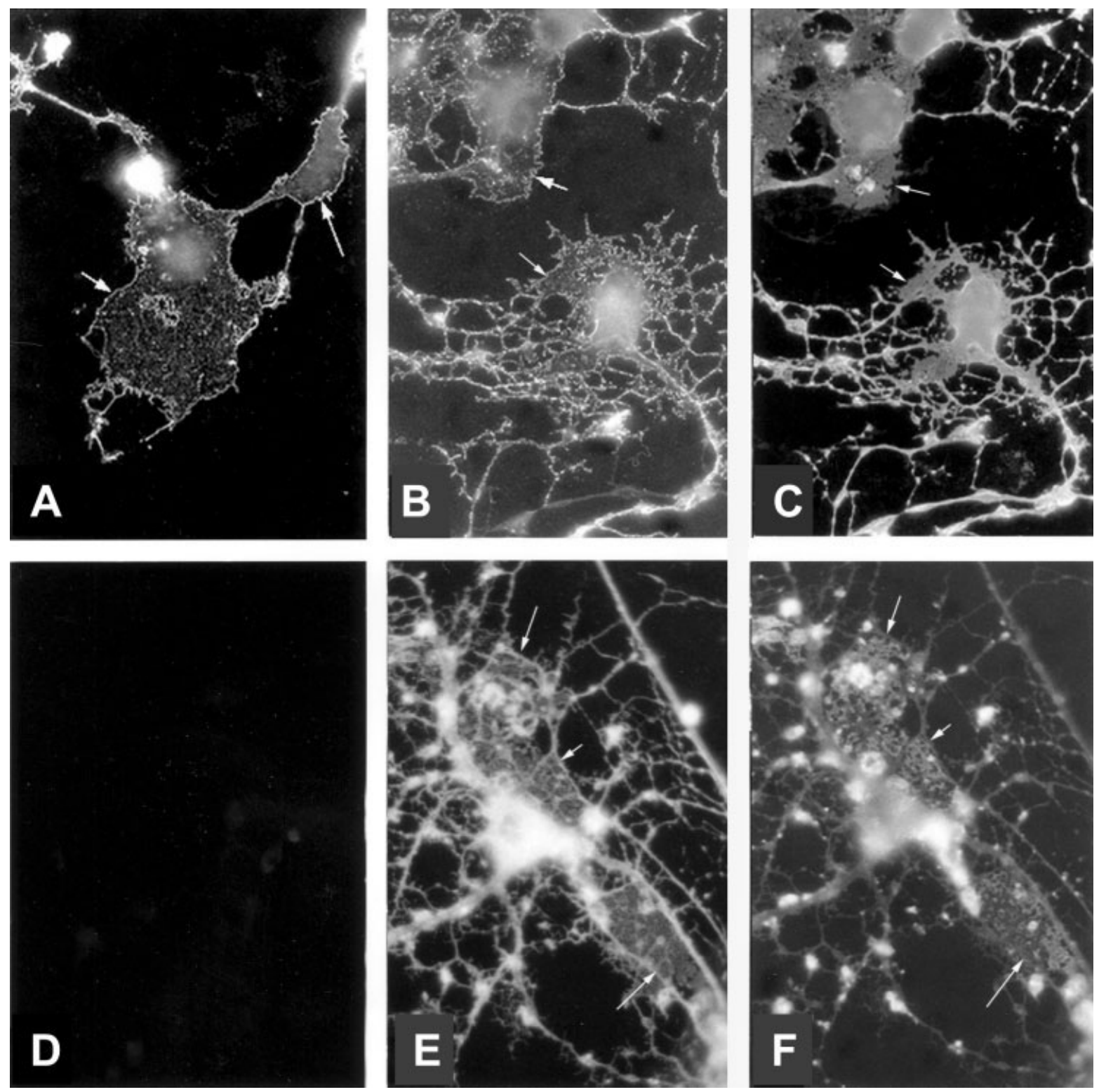

Fig. 2. Surface and internal staining of PLP epitopes in oligodendrocytes. A,B: Staining of live cultured oligodendrocytes with an anti50-69 mAb. Arrows indicate intensely stained perimeter of the membrane. C: Same cell as in B stained for O4 showing diffuse staining. Arrows in $\mathrm{B}$ and $\mathrm{C}$ indicate the same locations on the cell surface, demonstrating the difference between PLP and O4 staining. D:

ground neuropil. They did not stain neurons in this sample. There was similar specific staining of myelin bundles and individual fibers in all samples of cow, rabbit, rat, and mouse CNS tissues, consistent with the 95$100 \%$ identity with the human sequence of the PLP in these mammals (Greer and Lees, 1992). Figure 4 illustrates this staining pattern in rabbit basal ganglion. All mAbs also stained compact myelin in the barn owl brain. Although the PLP sequence is not known for the barn owl, the PLP sequences of other avian species (chicken
Staining of live oligodendrocyte cultures with anti-264-276 mAb; note lack of stain. E: Fixed and permeabilized oligodendrocyte stained with the anti-264-276 $\mathrm{mAb}$ shows diffuse PLP staining. F: Same cell as in E stained for MBP. Arrows in E and F point to cytoskeletal veins that are stained for the PLP epitope in E but not MBP in F. A-C: $\times 250$; D: $\times 150$; E,F: $\times 350$.

and zebra finch) are also highly conserved in most of the regions recognized by the mAbs (Campagnoni et al., 1994; Supplemental Tables A-C). Occasional staining of oligodendrocytes in gray matter, particularly with the mAbs to the C-terminus region, was also observed in the mammals and barn owl (not shown).

\section{Amphibian CNS Myelin}

All of the mAbs stained compact myelin in the Rana pipiens brain and spinal cord; the staining intensity 


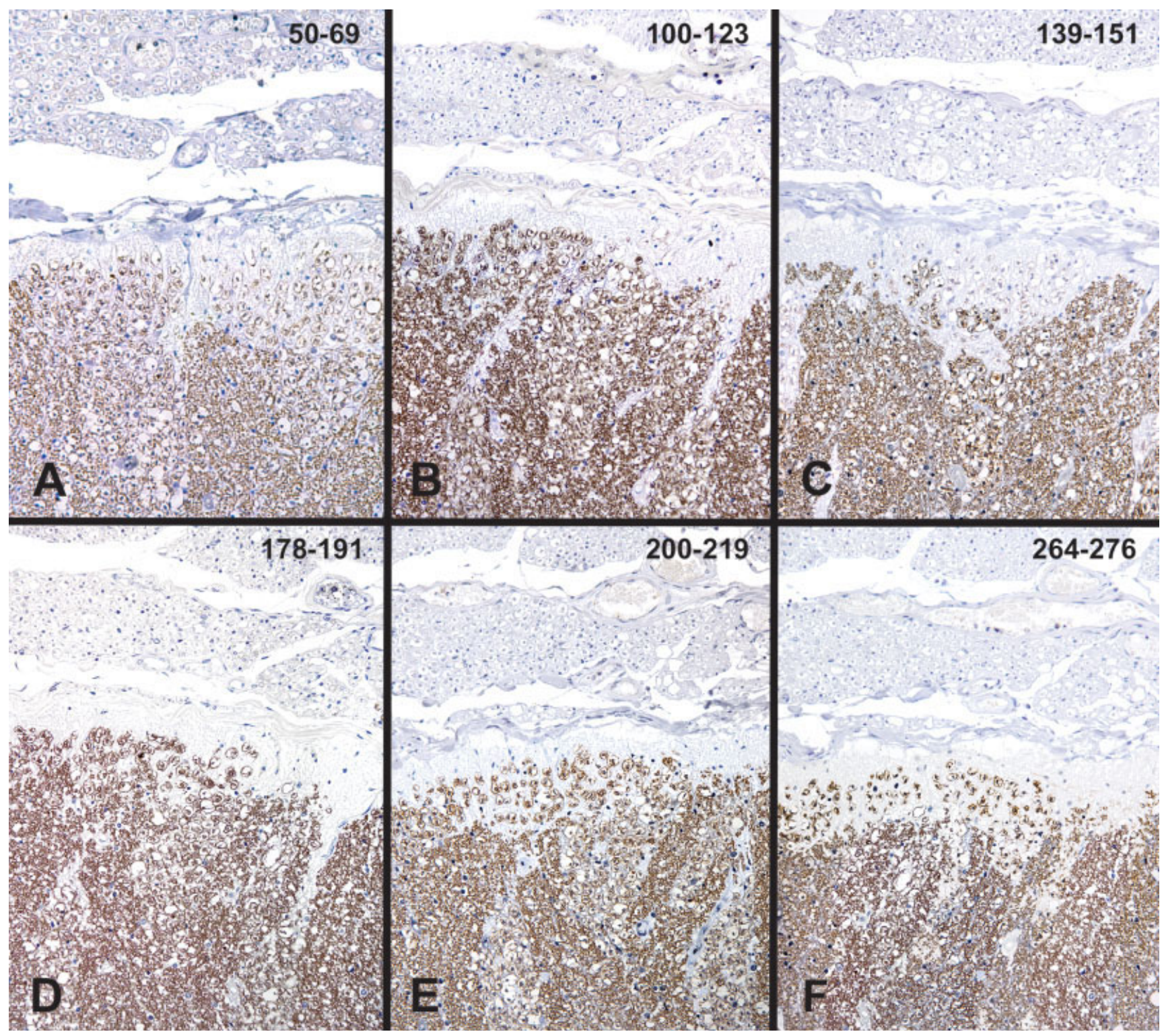

Fig. 3. Immunohistochemistry of a normal human spinal cord sample. Anterior spinal cord with spinal nerve roots (upper portion) and white matter (lower portion) shows specific staining of CNS myelin (brown) with the indicated $\mathrm{mAb}$ in each panel. PNS myelin, which lacks PLP, and nerve root axons (blue) are not stained. All are counterstained with hematoxylin. $\times 80$.

was greatest in myelinated fiber tracts of the cord (Figs. 5A-C, 9C). This pattern is consistent with the distribution of PLP in Xenopus (Yoshida et al., 1999). To our knowledge, pgf proteins in Rana pipiens have not been identified or sequenced. Therefore, staining correlations were made with Xenopus protein sequences (Supplemental Tables A-C). The Xenopus CNS samples studied were limited to the brain, and only staining of single myelinated fibers could be identified in those sections with all mAbs, except for $\mathrm{mAb}$ to 100-123 (Fig. $5 \mathrm{D}-\mathrm{F})$. The Xenopus PLP sequences are at least $80 \%$ identical to the human sequence in all regions analyzed, except 100-123 and 262-276. Xenopus pgf myelin proteins have approximately $50-60 \%$ identity with human PLP in the 100-123 and 264-276 regions. In the frog samples, therefore, the minimum sequence identity that resulted in recognition of compact CNS myelin by the anti-PLP mAbs was approximately $60 \%$.

\section{Teleost CNS Myelin}

The mAbs to 50-69, 200-219, and 264-276 immunostained CNS myelin in the Malawi cichlid brain (Fig. 6A,F,G). In these regions. there are considerable 


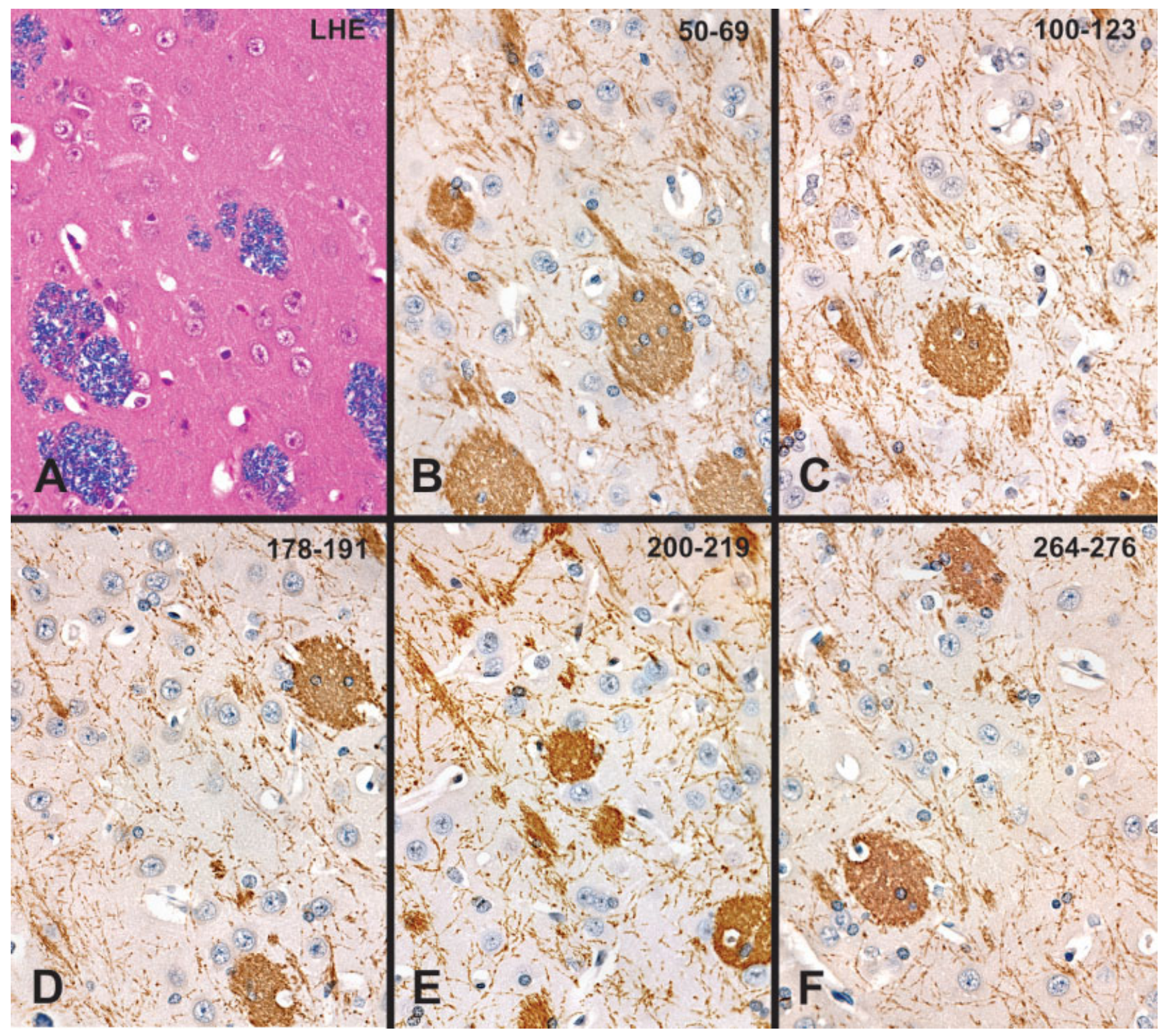

Fig. 4. Myelin staining in rabbit corpus striatum demonstrated by Luxol fast blue-hematoxylin and eosin (A) and by immunostaining for the indicated PLP epitopes (B-F). Dense fiber bundles and individual myelinated fibers but not the background neuropil or neurons are stained. This pattern is representative of the staining observed in all mammals and in the barn owl. $\times 160$.

similarities (approximately $50-75 \%$ identity) between the human PLP sequence and sequences of rainbow trout and zebrafish DM proteins (Supplemental Tables A, C). The anti-100-123 mAb did not stain the cichlid myelin (Fig. 6B), consistent with the expected absence of residues 116-150 in the major pgf myelin proteins in teleosts (Supplemental Table A). By contrast, both mAbs to the 139-151 region stained portions of the brain myelin in a distinct pattern, i.e., predominantly on fibers in peripheral portions of deep gray matter tract bundles, leaving larger central portions of the bundles unstained (Fig. 6C,D). The zebrafish DMy2 and the rainbow trout
DM-20 proteins have approximately 30-45\% identity with 139-151 (Supplemental Table B), but the implications and significance of this distinct partial staining pattern are presently unclear. The anti-178-191 mAb did not stain the cichlid myelin (Fig. 6E), despite the approximately $38 \%$ identity of rainbow trout DM-20 and the $54 \%$ identity of zebrafish DM $\gamma 2$ with the human PLP 178-191 sequence. The species of Malawi cichlid tested and its DM sequences are not known, and pgf myelin protein sequences are more diverse in teleosts than in tetrapods (Geltner et al., 1998). In summary, the $\mathrm{mAbs}$ to highly conserved regions, i.e., those in which 


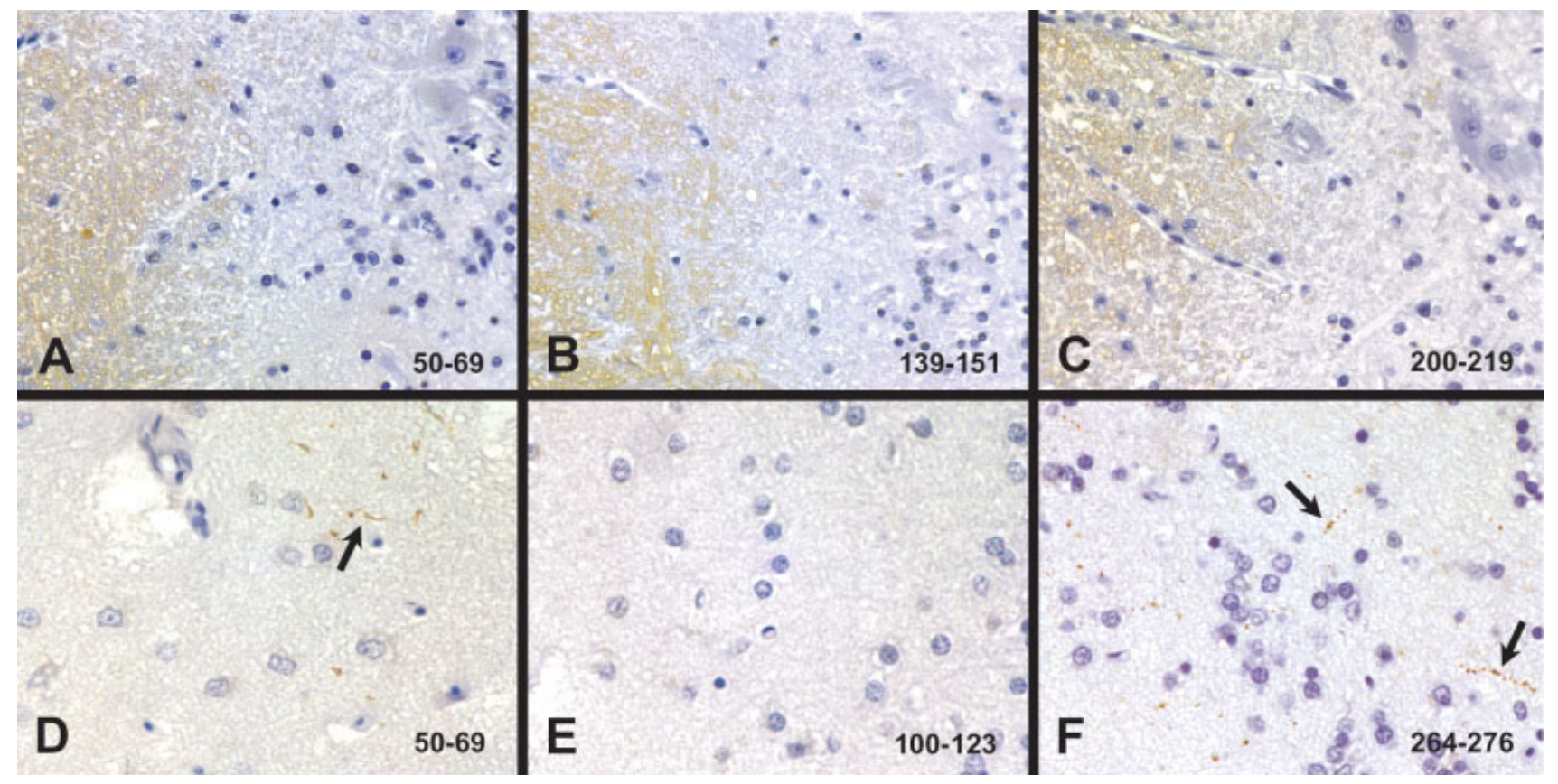

Fig. 5. mAb staining in Rana pipiens and Xenopus. Myelinated fiber tracts are stained with $\mathrm{mAbs}$ to the indicated epitopes in Rana pipiens spinal cord (A-C). Large neurons in these fields (upper right corners) are not stained. In Xenopus brain sections stained with mAbs to the indicated epitopes (DF), individual fibers are stained in beaded patterns for 50-69 and 264-276 (arrows in D,F). There is no staining for $100-123$ in E. A-C: $\times 160$; D-F: $\times 240$.

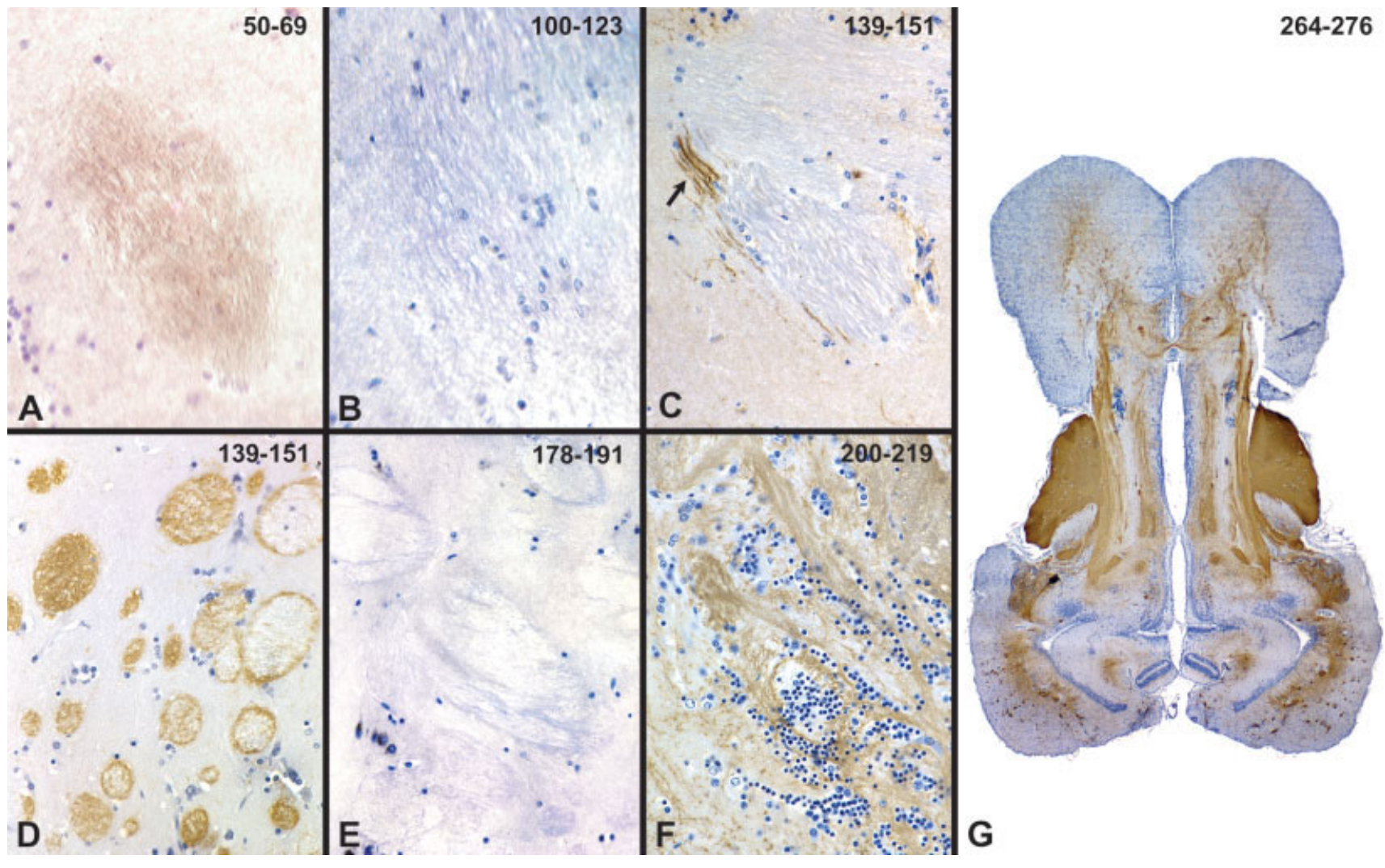

Fig. 6. $\mathrm{mAb}$ staining in Malawi cichlid brain. Compact myelin is stained with mAbs to 50-69 (A), 200-219 (F), and 264-276 (G, whole-brain section). No myelin is stained with mAbs to 100-123 (B) or 178-191 (E). Partial staining with two different anti-139-151 mAbs of peripheral portions of myelinated fiber bundles (arrow in $\mathrm{C}$ ) with central portions of the bundles remaining unstained is shown in C and D. A-F: $\times 160$; G: $\times 4$. 


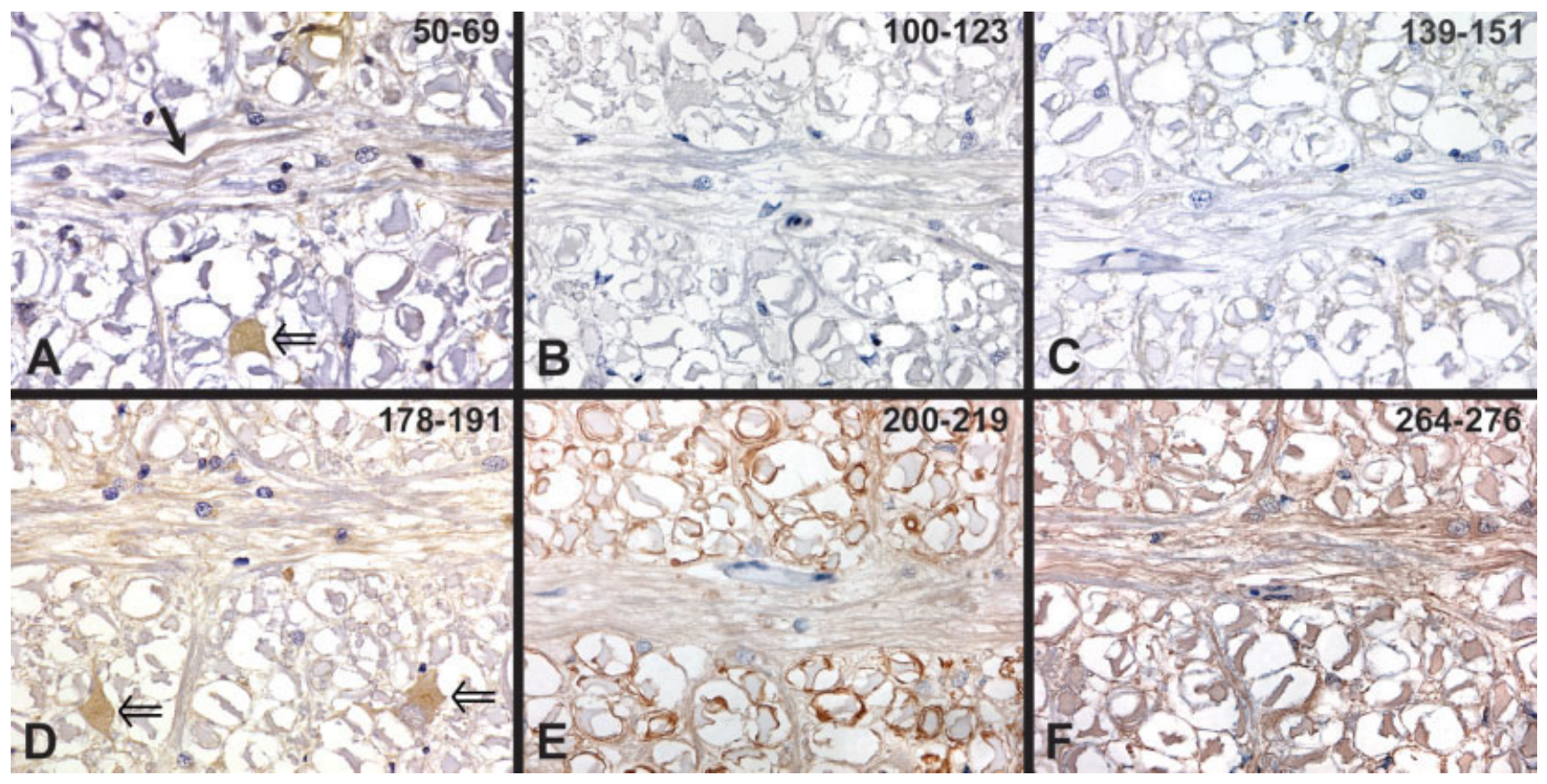

Fig. 7. $\mathrm{mAb}$ staining in leopard shark brainstem. Compact myelin is stained with $\mathrm{mAbs}$ to $50-69$ (solid arrow in A), 178-191 (D), 200-219 (E), and 264-276 (F). There is no staining with the $\mathrm{mAb}$ to $100-123(\mathbf{B})$, and the staining is minimal with an $\mathrm{mAb}$ to 139-151 (C). Additional neuron cell bodies are stained in A and D (open arrows). $\times 160$.

there is approximately $50 \%$ or greater identity of zebrafish and rainbow trout pgf proteins and PLP epitopes recognized at least some compact CNS myelin in the cichlid brain, whereas the mAbs to less well conserved regions were recognized to a lesser extent.

\section{Elasmobranch CNS Myelin}

The mAbs to the 50-69, 200-219, and 264-276 regions also immunostained compact myelin in the leopard shark brain (Fig. 7A,E,F). The sequences of squalus $\mathrm{DM} \alpha$ and $\mathrm{DM} \gamma$ are greater than $60 \%$ identical to the human PLP sequences in these regions (Supplemental Tables A, C). Myelin staining with the anti139-151 (Fig. 7C) and -178-191 (Fig. 7D) mAbs was positive although less uniform than the staining of the other mAbs; the squalus DM $\gamma$ sequences are approximately $46 \%$ and $61 \%$ identical to the human PLP 139 151 and 178-191 sequences, respectively (Supplemental Table B). The mAb to 100-123 did not stain the compact myelin (Fig. 7B), consistent with the absence of the PLP 116-150 sequence in elasmobranchs (Supplemental Table B).

\section{CNS Myelin Staining Correlations}

The left column in Table III summarizes the myelin staining and correlates positive staining results in each species tested with the percentage identities of the PLP $\mathrm{mAb}$ epitope and the most similar known pgf myelin
TABLE III. Summary of Myelin and Neuron Staining

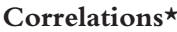

\begin{tabular}{lcc}
\hline $\begin{array}{l}\text { Identity of mAb epitope } \\
\text { and most similar pgf myelin } \\
\text { or neuronal protein (\%) }\end{array}$ & $\begin{array}{c}\text { Myelin staining } \\
\text { (No. positive/ } \\
\text { No. in group) }\end{array}$ & $\begin{array}{c}\text { Neuronal staining } \\
\text { (No. positive/ } \\
\text { No. in group) }\end{array}$ \\
\hline $0-29$ & $0 / 1$ & $0 / 4$ \\
$30-39$ & $0 / 1$ & $10 / 18$ \\
$40-49$ & $3 / 4$ & $9 / 16$ \\
$50-59$ & $4 / 5$ & $4 / 5$ \\
$\geq 60$ & $43 / 43$ & $3 / 11$ \\
Total positive/total & $50 / 54$ & $26 / 54$ \\
sequence comparisons & & \\
\hline
\end{tabular}

*Correlations of myelin and neuronal staining by the mAbs to six PLP regions in nine vertebrate species (54 correlations for each) with the extent of sequence identity of the epitopes with pgf proteins. The data are grouped according to the percentage identity of the $\mathrm{mAb}$ epitope and the most similar sequence in the known pgf myelin or neuronal proteins in each or the most closely related species (Table I). See Supplemental Tables A-C for specific correlations.

and neuronal proteins. Because there is a high degree of conservation of pgf myelin proteins, all 43 samples in which a pgf myelin protein is at least $60 \%$ identical to the human PLP epitope showed myelin staining with the mAbs. Staining was also very often observed when there was $40-60 \%$ identity of the mAb epitope and the corresponding sequence in the pgf myelin proteins of the species tested or the most closely related species. Staining was not observed when there was less than $40 \%$ 


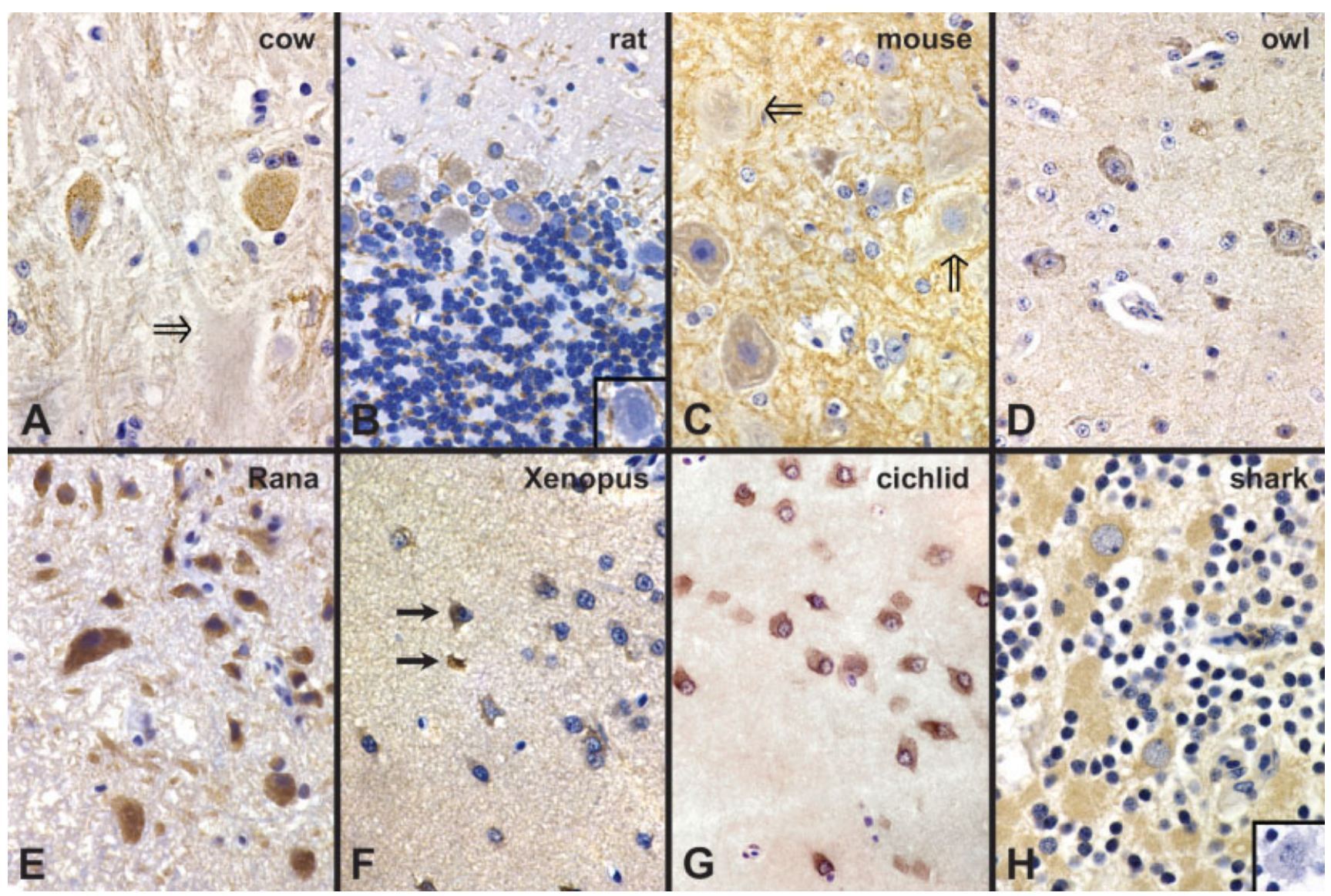

Fig. 8. Neuron subpopulations stained with the anti-178-191 mAb. A: Cow brainstem with adjacent cell in field (open arrow) unstained. B: Rat Purkinje cells are stained; granular layer neurons are not stained. Inset: Unstained Purkinje cell from adjacent section stained for 50-69 indicates epitope specificity. There is staining of individual myelinated fibers in both. C: Mouse ventral horn cells with adjacent cells in field (open arrows) showing little or no staining. D: Many large neurons in the barn owl forebrain show peripheral soma stain- ing. E: Large neurons in the Rana pipiens spinal cord are diffusely stained. F: Neurons in Xenopus brain (arrows) are stained. Unstained cells are seen in the same field. G: All neurons in this field from the cichlid brain are stained. $\mathbf{H}$ : Large Golgi-like neurons in the leopard shark cerebellar granular layer are stained, and there is diffuse staining of neuropil fibers. Inset: Unstained large Golgi-like neuron with an anti-139-151 mAb indicates epitope specificity of the anti-178-191 $\mathrm{mAb}$ staining. $\times 240$. sequence identity or when the epitope was absent in the known pgf proteins.

\section{CNS Neuron Staining by the Anti-178-191 mAb in All Vertebrate Species}

In addition to CNS myelin, the anti-178-191 $\mathrm{mAb}$ unexpectedly immunostained neuron subpopulations in all species tested. This positive staining included but was not limited to rare large neurons in the bovine brainstem (Fig. 8A)1 temporal cortical neuron subpopulations in the rabbit, rat, and mouse; Purkinje cells in the rat (Fig. 8B); ventral horn cell subpopulations in mouse spinal cord (Fig. 8C); many large gray matter neurons in the barn owl (Fig. 8D); large neurons in the spinal cord and brains of the frogs (Fig. 8E,F); and many neurons and neuropil in the cichlid and shark brains (Fig. 7D, 8G,H). The specificity of this staining was indicated by identification of unstained similarappearing neurons in the same microscopic fields (e.g., Fig. $8 \mathrm{~A}-\mathrm{C}, \mathrm{F})$, and the absence of staining of the same neuron subpopulations with the other $\mathrm{mAbs}$ in adjacent serial tissue sections (e.g., insets in Fig. $8 \mathrm{~B}, \mathrm{H}$ ) and in negatively staining controls.

The staining patterns of individual neurons were variable in different regions, but individual subpopulations tended to have uniform staining patterns in the same anatomic areas across species. For example, in most neurons in the mammals and barn owl, the immunoperoxidase reaction product appeared to be localized on soma membranes, with less staining around nuclei (Fig. 8B-D). In other species and anatomic regions, neuron cell bodies were more often diffusely stained (Fig. 8A,E-H). Axonal staining could generally not be assessed because of intense myelin staining. However, nonmyelinated, i.e., Luxol fast blue-negative, neuropil also showed diffuse staining, e.g., 


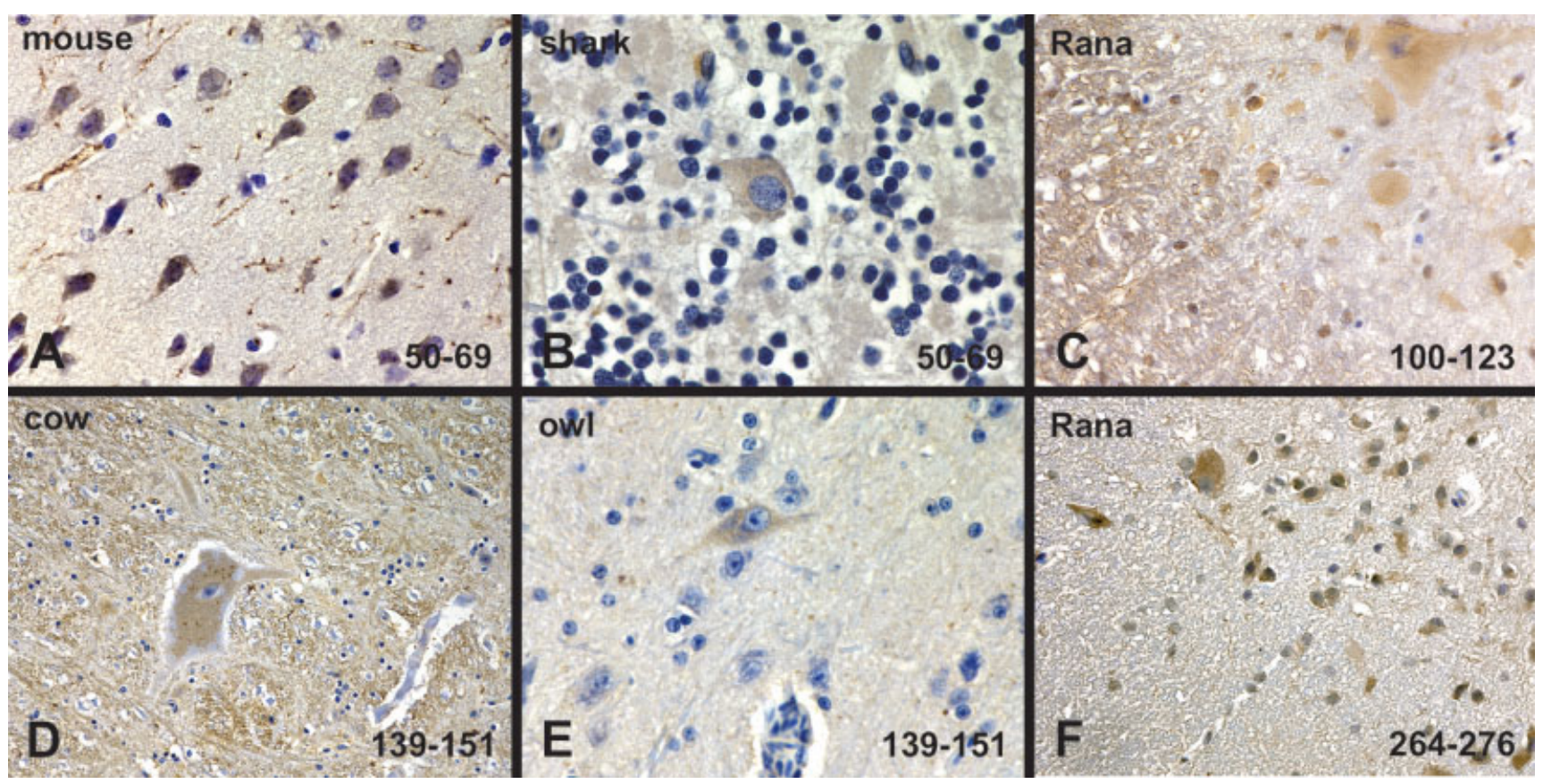

Fig. 9. CNS neuron staining with mAbs to epitopes other than 178 191. A: Mouse temporal cortex with many neurons stained for 50 69. B: A large Golgi-like neuron in the leopard shark cerebellar granular layer is stained with an anti-50-59 mAb. Absence of neuropil staining indicates specific neuronal soma staining and contrasts with Figure 8 H. C: Neurons and myelin are stained for 100-123 in
Rana pipiens spinal cord (note contrast to Fig. 5B,C). D: Large neuron in the cow brainstem stains for 139-151. E: A single neuron stains for 139-151 in the barn owl ventral brainstem. F: Numerous neurons are stained for 264-276 in the Rana pipiens spinal cord. A,B,E: $\times 240 ;$ C,F: $\times 160 ;$ D: $\times 80$.

brain (see, e.g., Fig. 7A) and cerebellum (Fig. 9B). This PLP region has approximately 30-60\% identity with sequences in mouse M6b, Xenopus DMy1 and DM 2 2/ GPM6b, zebrafish M6a, and squalus DM proteins (Supplemental Table A).

The anti-100-123 mAb stained ventral horn cells in the Rana pipiens spinal cord (Fig. 9C) and faintly stained some neurons in the leopard shark brain but did not stain neurons in any other species. The 100-123 region has approximately $30-40 \%$ identity with Xenopus $D M \beta$ and DM $\gamma 2 /$ M6b and squalus DM $\beta$ (Supplemental Table A).

One of the anti-139-151 mAbs (1C5) immunostained a subset of of neurons in the brainstems of the rabbit, rat, and cow (Fig. 9D); both of the anti-139-151 mAbs stained similar neurons in the barn owl ventral brainstem (Fig. 9E). The 139-151 region has a high degree of identity (46\%) with human, mouse, and chicken M6b sequences and with the sequence of Rhombex-29, a pgf neuronal protein that has been identified in the rat ventral medulla and is involved in $\mathrm{H}^{+}$channels and the regulation of sensitivity to acidosis (Shimokawa and Miura, 2000; Shimokawa et al., 2005; Supplemental Table B). Neurons of the other species were not stained with the anti-139-151 mAbs.

The mouse anti-264-276 mAb stained rare neurons in the bovine and barn owl brainstem and a subset of ventral horn cells in mouse spinal cord. The rat anti- 
262-276 mAb stained these populations and additionally stained neurons in the Rana pipiens spinal cord (Fig. 9F) and Xenopus and shark brains. Staining of rat caudal brainstem neurons with this $\mathrm{mAb}$ has also previously been demonstrated (Miller et al., 2003). This PLP region has from approximately $33 \%$ to $61 \%$ identity with most of the known M6 and DM sequences and with the Rhombex-29 sequence (Supplemental Table C).

\section{CNS Neuron Staining Correlations}

The right column of Table III summarizes the results of neuronal staining and groups them according to the percentage identities of the PLP $\mathrm{mAb}$ epitope and the most similar known pgf neuron protein(s). For example, there was from $40 \%$ to $49 \%$ identity between a PLP $\mathrm{mAb}$ epitope and the most similar known pgf neuronal protein in 16 samples. An anti-PLP $m A b$ stained neurons in nine of these. The mAbs to the six PLP regions recognized neurons in nearly half (26 of 54) of the samples tested. Neuron staining was observed frequently in samples in which there is greater than 30\% sequence identity of the PLP mAb epitope and the corresponding sequence in the pgf neuron proteins of the species tested or the most closely related species. However, despite high degrees of sequence similarity between PLP sequences and corresponding neuronal proteins, cross-reactivity was not invariably observed. In particular, the PLP 200-219 sequence and most species M6 and DM proteins are $60-75 \%$ identical but the $\mathrm{mAb}$ to this region did not react with neurons of any species (Supplemental Table C). Thus, a minimal sequence identity of approximately 30\% appears to be necessary but it may not be sufficient for neuronal epitope recognition by an anti-PLP Ab.

\section{DISCUSSION}

\section{Generation of Anti-PLP mAbs}

We have used a novel strategy to generate a panel of $\mathrm{mAbs}$ recognizing different regions of PLP and have demonstrated their usefulness in elucidating patterns of antiPLP antibody recognition of myelin and neurons in vertebrate CNS tissues. Immunization of $\mathrm{PLP}^{-1-}$ mice circumvented immunologic tolerance arising from the identity of human and murine PLP and its expression in lymphoid tissues (Voskuhl, 1998; Klein et al., 2000; Anderson and Kuchroo, 2003). Indeed, most of the PLP-reactive hybridomas were obtained from fusions using $\mathrm{PLP}^{-1-}$ mice. Immunization of the mice with whole PLP initiated the immune response, and boosting them with synthetic peptides induced expansion of B-cell clones reactive with specific regions of the protein. Therefore, this strategy facilitated production of $\mathrm{mAbs}$ that recognize PLP regions to which $m A$ bs have been difficult to obtain.

We and others have previously generated both polyclonal and mAbs to PLP. Potter and Lees (1988) immunized rabbits with a series of synthetic PLP peptides and obtained polyclonal sera reactive with specific regions of PLP (residues 48-59, 97-105, 183-193, 192-
200, and 264-276) on immunoblots. That study suggested a conformational dependence of antibody recognition of PLP. Gunn et al. (1990) identified the carboxy terminus of PLP as the immunodominant B-cell epitope and raised polyclonal rat antibodies to this region. Yamamura et al. (1991) immunized Lewis rats with PLP and generated mAbs specific for PLP 209-217 and PLP 264276. Konola et al. (1992) showed that one of these $\mathrm{mAbs}$ to the C-terminus, $\mathrm{mAb} A B 3$, recognized the cytoplasmic face of myelin. These mAbs were useful for localizing PLP-expressing cells in the CNS. Greer et al. (1996b) immunized different strains of mice with synthetic PLP peptides known to be encephalitogenic in each strain and generated mAbs to four regions of PLP (residues 40-59, 139-151,178-191, and 215-232). Immunofluorescent staining with these mAbs helped to verify the PLP orientation by identifying regions of PLP that are expressed on the outer or inner surface of the cell membrane. None of the mAbs generated in that study proved useful for immunoblotting, and several of them have been lost.

It is striking that, in previous attempts and in the present study, it has not been possible to obtain antibodies to the N-terminal region. A possible explanation may be that the primary structure of PLP precludes immune recognition of this portion of the molecule. This region contains six half-cystines within the first 36 amino acids, and these might shield reactions or limit the flexibility of the native protein (Oteiza et al., 1987; Potter and Lees, 1988).

\section{mAb Characterization}

The mAbs generated in the present study and analyzed in detail recognize human and bovine PLP by ELISA, and each recognizes a different region of PLP. Unlike the mAbs previously generated, all of these mAbs also recognize whole PLP on immunoblots, and all but one of them recognize DM-20. Since the anti-100-123 $\mathrm{mAb}$ F4.2D2 recognizes an epitope within the 116-150 region found in PLP but absent in DM-20, it distinguishes PLP from DM-20.

The mAb to PLP 50-69 tested recognized PLP on the surface of live, unfixed oligodendrocytes, thereby confirming the previous results of Greer et al. (1996b) showing that this region is on the external face of the membrane. However, the anti-178-191 mAb generated in that study also stained live oligodendrocytes, whereas the anti-178-191 mAb generated in the present study did not. One possible explanation is that those two anti178-191 mAbs do not recognize the same conformation. Additionally, the 178-191 region of PLP is relatively hydrophobic and may be partially buried in the cell membrane, thus preventing the binding to the cell surface epitope necessary for live staining.

In archival paraffin sections of a normal human spinal cord, the anti-PLP mAbs generated both in the present study and in previous studies showed specific immunostaining of human CNS but not PNS myelin 
(Fig. 3). These results are consistent not only with the immunoblot and in vitro oligodendrocyte staining data but also indicate that routine tissue processing does not preclude PLP epitope recognition by the mAbs. Consequently, a phylogenetic analysis of in situ PLP epitope recognition was feasible.

\section{mAb Recognition of CNS Myelin}

The mAbs stained compact CNS myelin in all mammalian species and the barn owl. Examples of this staining in the rabbit corpus striatum are shown in Figure 4. In the other species, highly conserved epitopes, i.e., those with greater than $40 \%$ identity with PLP, were also recognized, whereas less well conserved epitopes and those known to be absent from CNS myelin were not (Figs. 5-7, Table III, Supplemental Tables AC). In particular, the anti-100-123 mAb did not stain the cichlid or leopard shark myelin, which is consistent with the absence of the 116-150 region in the major myelin DM proteins of teleosts and elasmobranchs. These observations further confirm the specificity of the PLP epitope recognition in situ by the individual $\mathrm{mAbs}$. Moreover, they indicate that, although most of the PLP sequences are highly conserved across species, as little as $40 \%$ sequence identity between an $\mathrm{mAb}$ epitope and the known pgf major myelin proteins in each species appeared to be sufficient for myelin staining. This suggests a high degree of evolutionary conservation of pgf myelin epitopes in situ despite considerable sequence diversity among pgf myelin proteins in nonmammalian species (Campagnoni et al., 1994; Geltner et al., 1998). It is possible, however, that there are additional pgf or other classes of proteins that have not yet been identified in the various species that have greater sequence identity with the human $\mathrm{mAb}$ epitopes. The present data provide information only on the apparent minimal degree of sequence identity of the human PLP epitopes and currently known proteins that may account for the immunostaining results. It should also be emphasized that sequence identities are only surrogate assessments of the similarities among the mAb epitopes. The actual conformation-dependent binding interactions in situ cannot be assessed by current techniques.

\section{mAb Recognition of Neurons}

In addition to staining CNS myelin, the $\mathrm{mAb}$ to PLP 178-191 (P7.6A5) and to a lesser extent the other mAbs stained various CNS neuron subpopulations in all species. Neuronal recognition generally correlated with sequence identity of the anti-PLP $\mathrm{mAb}$ epitopes with known neuronal pgf proteins, such as the M6a and $-\mathrm{b}$ and DM $\beta$ proteins and Rhombex-29 (Supplemental Table B). We have also observed that several of these mAbs also immunostain embryonal rat hippocampal neurons grown in vitro (unpublished observations). These data imply that the staining might be due to recognition of conserved epitopes in pgf neuronal proteins. In view of the large number of pgf transcripts in oligodendro- cytes and neurons identified to date (Bongarzone et al., 1999; Werner et al., 2001), however, multiple potential epitopes could be recognized. For example, the anti139-151 (Fig. 9D,E) and anti-264-276 mAbs stained small numbers of neurons in the ventral brainstem of mammals and the barn owl. There is a relatively high degree of sequence identity with rat Rhombex-29 in these PLP regions, suggesting that the stained neurons might be a specific chemosensitive Rhombex-29expressing population (Miller et al., 2003; Shimokawa et al., 2005). On the other hand, M6 proteins, particularly M6a, are abundant in mature neurons in the cerebellar granular layer (Yan et al., 1993, 1996; Roussel et al., 1998), and we did not observe widespread staining in that anatomic region with any of the mAbs, suggesting that they might not recognize M6a protein epitopes. Moreover, the staining patterns of the neurons were variable, further indicating that different epitopes in different subpopulations may be expressed and recognized by the mAbs. The present study was not designed as a detailed comparison of specific populations, and it was not possible to compare staining patterns in neurons systematically among the different species. Furthermore, the CNS tissue samples available from each species were limited to certain anatomic regions, e.g., the bovine brainstem, and the extent of antibody recognition of neuron populations in each species may be greater than the present results indicate. For all of these reasons, therefore, although the neuron staining by the various $\mathrm{mAbs}$ is specific to distinct subpopulations and likely involves recognition of conserved pgf epitopes, at this time there is considerable uncertainty regarding the identity of the neuronal proteins recognized.

Shared antigens among nonmammalian and mammalian neural cell populations are increasingly being identified (Gould et al., 1995; Morris et al., 2004). These observations imply evolutionary acquisition of new protein functions (Aharoni et al., 2005), which appears to have been the evolutionary progression of the pgf proteins among marine and terrestrial vertebrates (Kitagawa et al., 1993). James et al. (2003) have suggested that conformational diversity, i.e., one sequence adopting multiple structures and functions, as in the conserved sequences among pgf proteins, can increase the numbers of potential antibody targets, thereby enhancing the likelihood of developing cross-reactivity, which can result in autoimmunity (Cohn, 2005). Our present results may also be consistent with that proposition.

\section{Implications for MS}

Widespread immunohistochemical staining of neuronal subpopulations by anti-PLP epitope mAbs suggests possible pathogenetic roles for anti-PLP antibodies that are found in humans with demyelinating diseases. Antimyelin component antibodies generated under pathological conditions might have either adverse or beneficial effects (van der Veen et al., 1986, 1989; Endoh et al., 1986; Sadler et al., 1991; Potter and Stephens, 1994; 
Genain et al., 1995; Laman et al., 2001; Morris-Downes et al., 2002; Mitsunaga et al., 2002; Schwab, 2004). Moreover, potential pathogenetic roles for antimyelin antibodies, including anti-PLP antibodies, have been suggested in MS (Sun et al., 1991; Warren et al., 1994; Sellebjerg et al., 1995, 2000; Archelos et al., 2000; Carvalho et al., 2003; Berger et al., 2003; Qin et al., 2003; Kanter et al., 2005; Zhang et al., 2005a). Furthermore, recent studies implicate an autoantibody to nonmyelinating cell populations in the pathogenesis of the MS variant neuromyelitis optica (Lennon et al., 2005) and specific antibody localization on axons in MS plaques (Zhang et al., 2005b). Our present results imply that anti-PLP antibodies that may arise in association with epitope spreading following myelin damage could simultaneously cross-react with neurons in vivo. The possible functional consequences of cross-reactivity of antibodies to pgf epitopes are suggested by the demonstration that an anti-M $6 \mathrm{mAb}$ inhibits neurite extension of mouse brain cells (Lagenaur et al., 1992) and suppresses neuronal differentiation of M6-transfected PC12 cells (Mukobata et al., 2002). We have also found that some of the anti-PLP mAbs generated in the present study inhibit neurite outgrowth in vitro (unpublished observations). Neuronal recognition by cross-reactive anti-PLP epitope antibodies might, therefore, similarly contribute to neuronal injury, altered function, or the failure of axon regeneration in MS patients. Thus, our results suggest a self-molecular-mimicry mechanism (Oldstone, 1998) that might contribute to the axonal injury and loss that are now considered to be major determinants of clinical expression and disease progression in MS (Trapp et al., 1999; Sobel, 2005). Whether there are autoantibody responses to PLP epitopes that simultaneously recognize other pgf proteins and have functional effects on neurons in vivo remains to be established.

In summary, we report the generation and characterization of novel anti-PLP epitope mAbs and have proved their usefulness as probes for demonstrating the remarkable evolutionary conservation of pgf protein epitopes in myelin and neurons. The present results also raise many new questions regarding the potential pathogenetic significance of anti-PLP antibodies that crossreact with neurons and may promote neuronal injury or prevent neuronal regeneration in human demyelinating diseases.

\section{ACKNOWLEDGMENTS}

The authors gratefully acknowledge Klaus-Armin Nave for PLP ${ }^{-1-}$ mice. We also thank Julie Kieu and Jessica Fant for technical assistance. Samples of bovine, avian, elasmobranch, amphibian, and teleost CNS tissue were kindly provided by Drs. Corrine Davis (Department of Comparative Medicine, Stanford University School of Medicine), Norman Lehman and Peter Jackson (Department of Pathology, Stanford University School of Medicine), and Stephen DeArmond (Depart- ment of Pathology, University of California San Francisco). This study was supported by NIH grants NS 046414 (to R.A.S.) and grants NS 30843 and P01 NS 38037 (to V.K.K.) and by The Stanley Foundation for Medical Research institute grant 02R-270 (to O.K.).

\section{REFERENCES}

Aharoni A, Gaidukov L, Khersonsky O, Gould SMQ, Roodveldt C, Tawfik DS. 2005. The "evolvability" of promiscuous protein functions. Nat Genet 37:73-76.

Anderson AC, Kuchroo VK. 2003. Expression of self-antigen in the thymus: a little goes a long way. J Exp Med 198:1527-1629.

Archelos JJ, Storch MK, Hartung HP. 2000. The role of B cells and autoantibodies in multiple sclerosis. Ann Neurol 47:694-706.

Berger T, Rubner P, Schautzer F, Egg R, Ulmer H, Mayringer I, Dilitz E, Deisenhammer F, Reindl M. 2003. Anti-myelin antibodies as a predictor of clinically definite multiple sclerosis after a first demyelinating event. N Engl J Med 349:139-145.

Bongarzone ER, Campagnoni CW, Kampf K, Jacobs EC, Handley VW, Schonmann V, Campagnoni AT. 1999. Identification of a new exon in the myelin proteolipid protein gene encoding novel protein isoforms that are restricted to the somata of oligodendrocytes and neurons. J Neurosci 19:8349-8357.

Campagnoni CW, Skoff RP. 2001. The pathobiology of myelin mutants reveal novel biological functions of the MBP and PLP genes. Brain Pathol 11:74-91.

Campagnoni CW, Kampf K, Mason B, Handley VW, Campagnoni AT. 1994. Isolation and characterization of a cDNA encoding the Zebra Finch myelin proteolipid protein. Neurochem Res 19:1061-1065.

Carvalho A, Sant'anna G, Santos CC, Frugulhetti IP, Leon SA, QuíricoSantos T. 2003. [Determination of autoantibody for myelin antigens in the serum of patients HLA-DQB1 · 0602 with multiple sclerosis]. Arq Neuropsiquiatr 61:968-973.

Cohn M. 2005. Degeneracy, mimicry and crossreactivity in immune recognition. Mol Immunol 42:651-655.

Dyer CA, Philibotte TM, Billings-Gagliardi S, Wolf MK. 1995. Cytoskeleton in myelin-basic-protein-deficient shiverer oligodendrocytes. Dev Neurosci 17:53-62.

Endoh M, Tabira T, Kunishita T. 1986. Antibodies to proteolipid apoprotein in chronic relapsing experimental allergic encephalomyelitis. J Neurol Sci 73:31-38.

Geltner D, Kitagawa K, Yoshida M. 1998. Remarkable diversity of proteolipid proteins in fish. J Neurosci Res 54:289-295.

Genain CP, Nguyen M-H, Letvin NL, Pearl R, Davis RL, Adelman M, Lees MB, Linington C, Hauser SL. 1995. Antibody facilitation of multiple sclerosis-like lesions in a nonhuman primate. J Clin Invest 96:2966-2974.

Gould RM, Fannon AM, Moorman SJ. 1995. Neural cells from dogfish embryos express the same subtype-specific antigens as mammalian neural cells in vivo and in vitro. Glia 15:401-408.

Gow A. 1997. Redefining the lipophilin family of proteolipid proteins. J Neurosci Res 50:659-664.

Greer JM, Lees MB. 2002. Myelin proteolipid protein-the first 50 years. Int J Biochem Cell Biol 34:211-215.

Greer JM, Sobel RA, Sette A, Southwood S, Lees MB, Kuchroo VK. 1996a. Immunogenic and encephalitogenic epitope clusters of myelin proteolipid protein. J Immunol 156:371-379.

Greer JM, Dyer CA, Pákáski M, Symonowicz C, Lees MB. 1996b. Orientation of myelin proteolipid protein in the oligodendrocyte cell membrane. Neurochem Res 21:431-440.

Greer JM, Klinguer C, Trifilieff E, Sobel RA, Lees MB. 1997. Encephalitogenicity of murine but not bovine DM20 in SJL/J mice is due to a single amino acid substitution. Neurochem Res 22:541-547. 
Griffiths I, Klugmann M, Anderson T, Thomson C, Vouyiouklis D, Nave K-A. 1998. Current concepts of PLP and its role in the nervous system. Microsc Res Techniq 41:344-358.

Gudz TI, Schneider TE, Hass TA, Macklin WB. 2002. Myelin proteolipid protein forms a complex with integrins and may participate in integrin receptor signaling in oligodendrocytes. J Neurosci 22:73987407.

Gunn CA, Richards MK, Linington C. 1990. The immune response to myelin proteolipid protein in the Lewis rat: identification of the immunodominant B cell epitope. J Neuroimmunol 27:155-162.

Jacobs EC, Bongarzone ER, Campagnoni CW, Kampf K, Campagnoni AT. 2003. Soma-restricted products of the myelin proteolipid gene are expressed primarily in neurons in the developing mouse nervous system. Dev Neurosci 25:96-104.

Jacobs EC, Bongarzone ER, Campagnoni CW, Campagnoni AT. 2004. Embryonic expression of the soma-restricted products of the myelin proteolipid gene in motor neurons and muscle. Neurochem Res 29: 997-1002.

James LC, Roversi P, Tawfik DS. 2003. Antibody multispecificity mediated by conformational diversity. Science 299:1362-1367.

Kanter J L, Narayana S, Ho PP, Catz I, Warren KG, Sobel RA, Steinman L, Robinson WH. 2005. Lipid microarrays identify key mediators of autoimmune brain inflammation. Nat Med (in press).

Kearney JF, Radbruch A, Liesegang B, Rajewsky K. 1979. A new mouse myeloma cell line that has lost immunoglobulin expression but permits the construction of antibody-secreting hybrid cell lines. J Immunol 123: $1548-1550$.

Kitagawa K, Sinoway MP, Yang CP, Gould RM, Colman DR. 1993. A proteolipid protein gene family expression in sharks and rays and possible evolution from an ancestral gene encoding a pore-forming polypeptide. Neuron 11:443-448.

Klein KL, Klugmann M, Nave K-A, Tuohy VK, Kyewski B. 2000. Shaping of the autoreactive T-cell repertoire by a splice variant of self protein expressed in thymic epithelial cells. Nat Med 5:56-61.

Klugmann M, Schwab MH, Puhlhofer A, Schneider A, Zimmerman F, Griffiths IR, Nave K-A. 1997. Assembly of CNS myelin in the absence of proteolipid protein. Neuron 18:59-70.

Kohler G, Milstein C. 1975. Continuous cultures of fused cells secreting antibody of predefined specificity. Nature 256:495-497.

Konola JT, Yamamura T, Tyler B, Lees MB. 1992. Orientation of the myelin proteolipid protein C-terminus in oligodendroglial membranes. Glia 5:112-121.

Lagenaur C, Kunemund V, Fischer G, Fushiki S, Schachner M. 1992. Monoclonal M6 antibody interferes with neurite extension of cultured neurons. J Neurol 23:71-88.

Laman JD, Visser L, Maassen CB, de Groot CJ, de Jong LA, t'Hart BA, van Meurs M, Schellekens MM. 2001. Novel monoclonal antibodies against proteolipid protein peptide 139-151 demonstrate demyelination and myelin uptake by macrophages in MS and marmoset EAE lesions. J Neuroimmunol 119:124-130.

Lennon VA, Kryzer TJ, Pittock SJ, Verman AS, Hinson SR. 2005. IgG marker of optic-spinal multiple sclerosis binds to the aquaporin-4 water channel. J Exp Med 202:473-477.

Marcovic-Plese S, Fukaura H, Zhang J, al-Sabbagh A, Southwood S, Sette A, Kuchroo VK, Hafler DA. 1995. T cell recognition of immunodominant and cryptic proteolipid protein epitopes in humans. J Immunol 155:982-992.

McCarthy KD, de Vellis J. 1980. Preparation of separate astroglial and oligodendroglial cell cultures from rat cerebral tissue. J Cell Biol 85: 890-902.

Miller MJ, Haxhiu MA, Georgiadis P, Gudz TI, Kangas CD, Macklin WB. 2003. Proteolipid protein gene mutation induces altered ventilatory response to hypoxia in the myelin-deficient rat. J Neurosci 23:22652273.
Mitsunaga Y, Ciric B, Van Keulen V, Warrington AE, Paz Soldan M, Bieber AJ, Rodriguez M, Pease LR. 2002. Direct evidence that a human antibody derived from patient serum can promote myelin repair in a mouse model of chronic-progressive demyelinating disease. FASEB J 16:1325-1327.

Morris JK, Willard BB, Yin X, Jeserich G, Kinter M, Trapp BD. 2004. The $36 \mathrm{~K}$ protein of zebrafish CNS myelin is a short-chain dehydrogenase. Glia 45:378-391.

Morris-Downes MM, Smith PA, Rundle JL, Piddlesden SJ, Baker D, Pham-Dinh D, Heijmans N, Amor S. 2002. Pathological and regulatory effects of anti-myelin antibodies in experimental allergic encephalomyelitis in mice. J Neuroimmunol 125:114-124.

Mukobata S, Hibino T, Sugiyama A, Urano Y, Inatomi A, Kanai Y, Endo H, Tashiro F. 2002. M6a acts as a nerve growth factor-gated $\mathrm{Ca}^{2+}$ channel in neuronal differentiation. Biochem Biophys Res Commun 297:722-728.

Oldstone MB. 1998. Molecular mimicry and immune-mediated diseases. FASEB J 12:1255-1265.

Oteiza PI, Adamo AM, Aloise PA, Paladini AC, Paladini AA, Soto EF. 1987. Cyst(e)ine residues of bovine white-matter proteolipid proteins. Role of disulphides in proteolipid conformation. Biochem J 245:507-513.

Pelfrey CM, Rudick RA, Cotleur AC, Lee JC, Tary-Lehmann M, Lehmann PV. 2000. Quantification of self-recognition in multiple sclerosis by single-cell analysis of cytokine production. J Immunol 165:1641-1651.

Pender MP, Csurhes PA, Greer JM, Mowat PD, Henderson RD, Cameron KD, Purdie DM, McCombe PA, Good MF. 2000. Surges of increased $\mathrm{T}$ cell reactivity to an encephalitogenic region of myelin proteolipid protein occur more often in patients with multiple sclerosis than in healthy subjects. J Immunol 165:5322-5331.

Potter NT, Lees MB. 1988. Immunochemical characterization of antibodies to the myelin proteolipid protein (PLP). J Neuroimmunol 18: 49-60.

Potter NT, Stephens TS. 1994. Humoral immune recognition of proteolipid protein (PLP)-specific encephalitogenic epitopes in the SJL/J mouse. J Neurosci Res 37:15-22.

Nicholson LB, Greer JM, Sobel RA, Lees MB, Kuchroo VK. 1995. An altered peptide ligand mediates immune deviation and prevents autoimmune encephalomyelitis. Immunity 3:397-405.

Qin Y, Duquette P, Zhang Y, Olek M, Da RR, Richardson J, Antel JP, Talbot P, Cashman NR, Tourtellotte WW, Wekerle H, Van Den Noort S. 2003. Intrathecal B-cell clonal expansion, an early sign of humoral immunity in the cerebrospinal fluid of patients with clinically isolated syndrome suggestive of multiple sclerosis. Lab Invest 83:10811088.

Roussel G, Trifilieff E, Lagenaur C, Nussbaum J-L. 1998. Immunoelectron microscopic localization of the M6a antigen in rat brain. J Neurocytol 27:695-703.

Sadler RH, Sommer MA, Forno LS, Smith ME. 1991. Induction of antimyelin antibodies in EAE and their possible role in demyelination. J Neurosci Res 30:616-624.

Schwab ME. 2004. Nogo and axon regeneration. Curr Opin Neurobiol 14:118-124.

Sellebjerg F, Madsen HO, Frederiksen JL, Ryder LP, Svejgaard A. 1995. Acute optic neuritis: myelin basic protein and proteolipid protein antibodies, affinity, and the HLA system. Ann Neurol 38:943-950.

Sellebjerg F, Jensen CV, Christiansen P. 2000. Intrathecal IgG synthesis and autoantibody-secreting cells in multiple sclerosis. J Neuroimmunol 108:207-215.

Shimokawa N, Miura M. 2000. Rhombex-29, a novel gene of the PLP/DM20-M6 family cloned from rat medulla oblongata by differential display. J Neurosci Res 62:1-8.

Shimokawa N, Dikic I, Sugama S, Koibuchi N. 2005. Molecular responses to acidosis of central chemosensitive neurons in brain. Cell Signal 17:799-808. 
Sobel RA. 2005. Ephrin A receptors and ligands in lesions and normalappearing white matter in multiple sclerosis. Brain Pathol 15:35-45.

Sun JB, Olsson T, Wang WZ, Xiao BG, Kostulas V, Fredrikson S, Ekre HP, Link H. 1991. Autoreactive T and B cells responding to myelin proteolipid protein in multiple sclerosis and controls. Eur J Immunol 21:1461-1468.

Trapp BD, Ransohoff R, Rudick R. 1999. Axonal pathology in multiple sclerosis: relationship to neurologic disability. Curr Opin Neurol 12: 295-302.

van der Veen RC, Sobel RA, Lees MB. 1986. Chronic experimental allergic encephalomyelitis and antibody responses in rabbits immunized with proteolipid protein. J Neuroimmunol 11:321-333.

van der Veen RC, Trotter JL, Clark HB, Kapp JA. 1989. The adoptive transfer of chronic relapsing experimental allergic encephalomyelitis with lymph node cells sensitized to myelin proteolipid protein. J Neuroimmunol 21:183-191.

Voskuhl R. 1998. Myelin protein expression in lymphoid tissues: implications for peripheral tolerance. Immunol Rev 164:81-92.

Warren KG, Catz I, Johnson E, Mielke B. 1994. Anti-myelin basic protein and anti-proteolipid protein specific forms of multiple sclerosis. Ann Neurol 35:280-289.

Werner H, Dimou L, Klugmann M, Pfeiffer S, Nave K-A. 2001. Multiple splice isoforms of proteolipid M6B in neurons and oligodendrocytes. Mol Cell Neurosci 18:593-605.
Yamamura T, Konola JT, Wekerle H, Lees MB. 1991. Monoclonal antibodies against myelin proteolipid protein: identification and characterization of two major determinants. J Neurochem 57:1671-1680.

Yan Y, Lagenaur C, Narayanan V. 1993. Molecular cloning of M6: identification of a PLP/DM20 gene family. Neuron 11:423-431.

Yan Y, Narayanan V, Lagenaur C. 1996. Expression of members of the proteolipid protein gene family in the developing murine central nervous system. J Comp Neurol 370:465-478.

Yool DA, Klugmann M, McLaughlin M, Vouyiouklis DA, Dimou L, Barrie JA, McCulloch MC, Nave K-A, Griffiths IR. 2001. Myelin proteolipid proteins promote the interaction of oligodendrocytes and axons. J Neurosci Res 63:151-164.

Yoshida M, Shan W-S, Colman DR. 1999. Conserved and divergent expression patterns of the proteolipid protein gene family in the amphibian central nervous system. J Neurosci Res 57:13-22.

Zhang Y, Da R-R, Guo W, Hilgenberg LG, Sobel RA, Tourtellotte WW, Smith MA, Olek M, Gupta S, Robertson RT, Nagra R, van den Noort S, Qin Y. 2005a. Axon reactive B cells clonally expanded in the cerebrospinal fluid of patients with multiple sclerosis. J Clin Immunol 25:254-64.

Zhang Y, Da R-R, Tourtellotte WW, Sobel RA, Ren H, Nagra R, Gupta S, van den Noort S, Qin Y. 2005b. Clonal expansion of IgApositive plasma cells and axon-reactive antibodies in multiple sclerosis lesions. J Neuroimmunol 167:120-30. 